\title{
A Nested-Grid Ocean Circulation Model for Simulating Three-Dimensional Circulation and Hydrography over Canadian Atlantic Coastal Waters
}

\author{
Jinyu Sheng ${ }^{1, *}$ and Bo Yang ${ }^{1,2}$ \\ ${ }^{1}$ Department of Oceanography, Dalhousie University,Halifax, Nova Scotia, Canada, B3H 4JI \\ ${ }^{2}$ Physical Oceanography Laboratory, Ocean University of China, Qingdao 266100, China
}

Received 8 September 2008, accepted 8 June 2009

\begin{abstract}
A one-way nested-grid coastal ocean circulation modeling system was developed for Canadian Atlantic coastal waters based on an operational prototype shelf circulation forecast system known as Dalcoast3 and a high-resolution coastal circulation model developed for Lunenburg Bay (LB) of Nova Scotia. The nested-grid system consists of five relocatable downscaling sub-models, including the outermost sub-model covering the eastern Canadian shelf with a coarse horizontal resolution of $1 / 12^{\circ}$, and the innermost sub-model covering LB with a fine resolution of about $180 \mathrm{~m}$. The nested-grid system is driven by meteorological forcing converted from three-hourly weather forecast fields provided by the Meteorological Service of Canada and tidal forcing produced by WebTide using pre-calculated tidal harmonic constants. The nested-grid system is used to simulate the dynamic response of coastal waters over the inner Scotian Shelf in June and July 2006. A comparison of model results with observations made in LB demonstrates that the NCOPS-LB performs reasonably well in simulating sea surface elevations and tidal currents, and less well in simulating hydrography and non-tidal currents over the inner shelf.
\end{abstract}

Key words: Nested-grid, Numerical modeling, Three-dimensional, Storm-induced, Coastal circulation, Eastern Canadian shelf Citation: Sheng, J. and B. Yang, 2010: A Nested-grid ocean circulation model for simulating three-dimensional circulation and hydrography over Canadian Atlantic coastal waters. Terr. Atmos. Ocean. Sci., 21, 27-44, doi: 10.3319/TAO.2009.06.08.01(IWNOP)

\section{INTRODUCTION}

Oceans play an important role in regulating the Earth's climate and influencing the global ecosystem. Contamination from various sources coupled with atmospheric changes and competing demands for natural marine resources are putting oceans, the world's oldest life-support system, in jeopardy (UNEP 1984). Coastal waters, which are defined as the narrow strip of ocean waters between the mean lower water mark at the coast and the outer edge of the continental shelf, have the highest rates of diversity and biological productivity in the world. Human activity, pollution, commercial fishing, offshore oil and gas exploration, structures on the sea-bed, and agricultural run-off from the land, significantly affect coastal ecosystem dynamics. Although many attempts have been made to protect coastal areas and to encourage sustainable coastal development, few have been successful (Brachya et al. 1994). This is mainly

\footnotetext{
* Corresponding author

E-mail: Jinyu.Sheng@Dal.Ca
}

because the most of previous efforts have largely been sectoral, and fierce competition exists for the use and management of coastal resources in many areas. Therefore, there is an urgent need for better knowledge of coastal dynamics in order to develop an ecosystem-based management of natural resources over coastal waters.

A coastal ocean observatory was established in the summer of 2000 in Lunenburg Bay (LB) in Lunenburg County, Nova Scotia as part of a multidisciplinary research program of marine environmental observation and prediction for Canadian Atlantic coastal waters known as CMEPBay (CMEP stands for the Centre for Marine Environmental Prediction, see Wang et al. 2007). The observatory was operational from the spring until fall over the 7-year period from 2002 to 2008. The main objective of CMEP-Bay was to develop a marine environmental observation and prediction system for Canadian Atlantic coastal waters, using coupled models guided directly by real-time observations (Wang et al. 2007). As part of CMEP-Bay, a high-resolution, limited-area coastal circulation model for Lunenburg 
Bay (CCM-Bay) was developed (Zhai et al. 2008a; Sheng et al. 2009). This coastal model has two sub-components with a high-resolution $(180 \mathrm{~m})$ inner sub-component nested inside a coarser-resolution $(500 \mathrm{~m})$ outer sub-component. The CCM-Bay was used successfully in simulating the three-dimensional currents and water mass distributions in LB in the summer and fall of 2003 (Zhai et al. 2008a) and calculating dispersion and physical connectivity of surface waters during Hurricane Juan in 2006 (Sheng et al. 2009).

In this study, we present a five-level nested-grid coastal ocean circulation modeling system known as the NCOPS-LB for Canadian Atlantic coastal waters based on the integration of Dalcoast 3 and CCM-Bay. The plan of the paper is as follows. Section 2 describes the setup and external forcing of the NCOPS-LB. Section 3 discusses the simulated three-dimensional circulation and temperature distributions over the inner Scotian Shelf in June 2006 using the NCOPS-LB. Section 4 assesses the performance of the NCOPS-LB based on the comparison of model results with in-site and satellite observations. The final section is a summary and conclusion.

\section{THE NESTED-GRID COASTAL OCEAN CIRCU- LATION MODELING SYSTEM}

The nested-grid coastal ocean circulation modeling system (NCOPS-LB) has five relocatable sub-models (Fig. 1, Table 1), which consists of (L1) a storm surge sub-model for the eastern Canadian shelf (ECS) and adjacent waters between 72 and $42^{\circ} \mathrm{W}$ and between 38 and $60^{\circ} \mathrm{N}$; (L2) a shelf circulation sub-model for the Gulf of St. Lawrence (GSL), the Scotian Shelf (SS), and adjacent slope waters between 67.5 and $56^{\circ} \mathrm{W}$ and between 41.75 and $52^{\circ} \mathrm{N}$; (L3) a limited-area shelf circulation sub-model for the inner Scotian Shelf between 62.88 and $64.4^{\circ} \mathrm{W}$ and between 43.8 and $44.79^{\circ} \mathrm{N}$; (L4) a coastal circulation sub-model for the 3-bay region of Mahone Bay (MB), Lunenburg Bay (LB) and Rose Bay (RB) of Nova Scotia; and (L5) a coastal circulation sub-model for Lunenburg Bay (LB). Sub-model L1 is twodimensional (2D) and barotropic (in which model temperature and salinity are set to a constant value everywhere) for simulating storm-surges and barotropic shelf waves over the ECS. The other four sub-models are three-dimensional (3D) and baroclinic for simulating three-dimensional currents and hydrographic distributions over the coastal and shelf waters of the ECS. The horizontal resolutions of the five sub-models are $1 / 12^{\circ}, 1 / 16^{\circ}, \sim 1.1 \mathrm{~km}, \sim 500$ and $\sim 180 \mathrm{~m}$, respectively. The main advantage of this nested-grid system is that its each sub-model has independent model grid setup and can be relocated to any coastal waters of the eastern Canadian shelf.

Sub-models L1 and L2 are the main components of the prototype operational shelf circulation prediction system known as Dalcoast3 (Thompson et al. 2007) construct- ed from the $\sigma$-level Princeton Ocean Model (POM, Mellor 2004, Table 1). Sub-model L2 uses 30 o-levels in the vertical, with various spacing between adjacent $\sigma$ levels doubling between the sea surface and the tenth $\sigma$-level at $\sigma=-0.0909$ and constant spacing of 0.0455 below the tenth $\sigma$-level. The subgrid scale mixing parameterizations used in Dalcoast 3 are the horizontal mixing scheme of Smagorinsky (1963) and the vertical turbulent closure scheme of Mellor and Yamada (1982). Sub-models 3 - 5 are constructed from the z-level ocean circulation model known as CANDIE (Canadian Version of Diecast, Sheng et al. 1998; Zhai et al. 2008a, Table 1) and use 24 z-levels in the vertical with a resolution of $1.0 \mathrm{~m}$ except for $3.0 \mathrm{~m}$ for the top z-level and $4.5 \mathrm{~m}$ below $20 \mathrm{~m}$ depth. These three sub-models (L3 - 5) use the vertical KPP mixing scheme of Large et al. (1994) for vertical eddy viscosity and diffusivity coefficients $K_{m}$ and $K_{h}$, and the horizontal mixing scheme of Smagorinsky (1963) for the horizontal eddy viscosity coefficient $A_{m}$, with the inverse (horizontal) turbulent Prandtl Number $A_{h} / A_{m}$ set to 0.1 (to make the model temperature and salinity to be less diffusive than the model momentum), where $A_{h}$ is the horizontal eddy diffusivity coefficient. The background horizontal eddy viscosity and diffusivity coefficients are set $10 \mathrm{~m}^{2} \mathrm{~s}^{-1}$.

The nested-grid system is driven by the meteorological and tidal forcing. The meteorological forcing used to drive the five sub-models of the nested-grid system includes atmospheric pressures at the mean sea level (SLP) and surface wind taken from the three-hourly numerical weather forecast fields produced by the Meteorological Service of Canada (MSC). The surface wind stress is converted from the MSC wind speeds using the bulk formula of Large and Pond (1981). The net heat flux $\left(Q_{n e t}\right)$ at the sea surface is calculated using the following bulk formula (Gill 1982):

$Q_{n e t}=Q_{I}+Q_{B}+Q_{L}+Q_{s}$

where $Q_{I}$ is the flux of sunlight into the ocean, $Q_{B}$ is the net upward flux of long-wave radiation from the ocean, $Q_{L}$ is the latent heat flux carried by evaporated water, and $Q_{S}$ is the sensible heat flux due to conduction. Each term on the right hand side of Eq. (1) is positive if the flux is from the atmosphere to the ocean. In this study $Q_{I}$ is taken from sixhourly NCEP fields, and $Q_{B}, Q_{L}$ and $Q_{S}$ are calculated using empirical formulas from the NCEP fields of air temperature, relative humidity and wind speed, model-calculated sea surface temperatures (SST), and an assumed constant cloud cover of 0.5 . The external forcing in sub-model L4 and L5 also includes an additional net surface heat (and freshwater) flux diagnosed from model results using the following (simple data-assimilation) procedure. We first run the NCOPS-LB with the net sea surface heat flux calculated by Eq. (1). We calculate differences between the modeled 


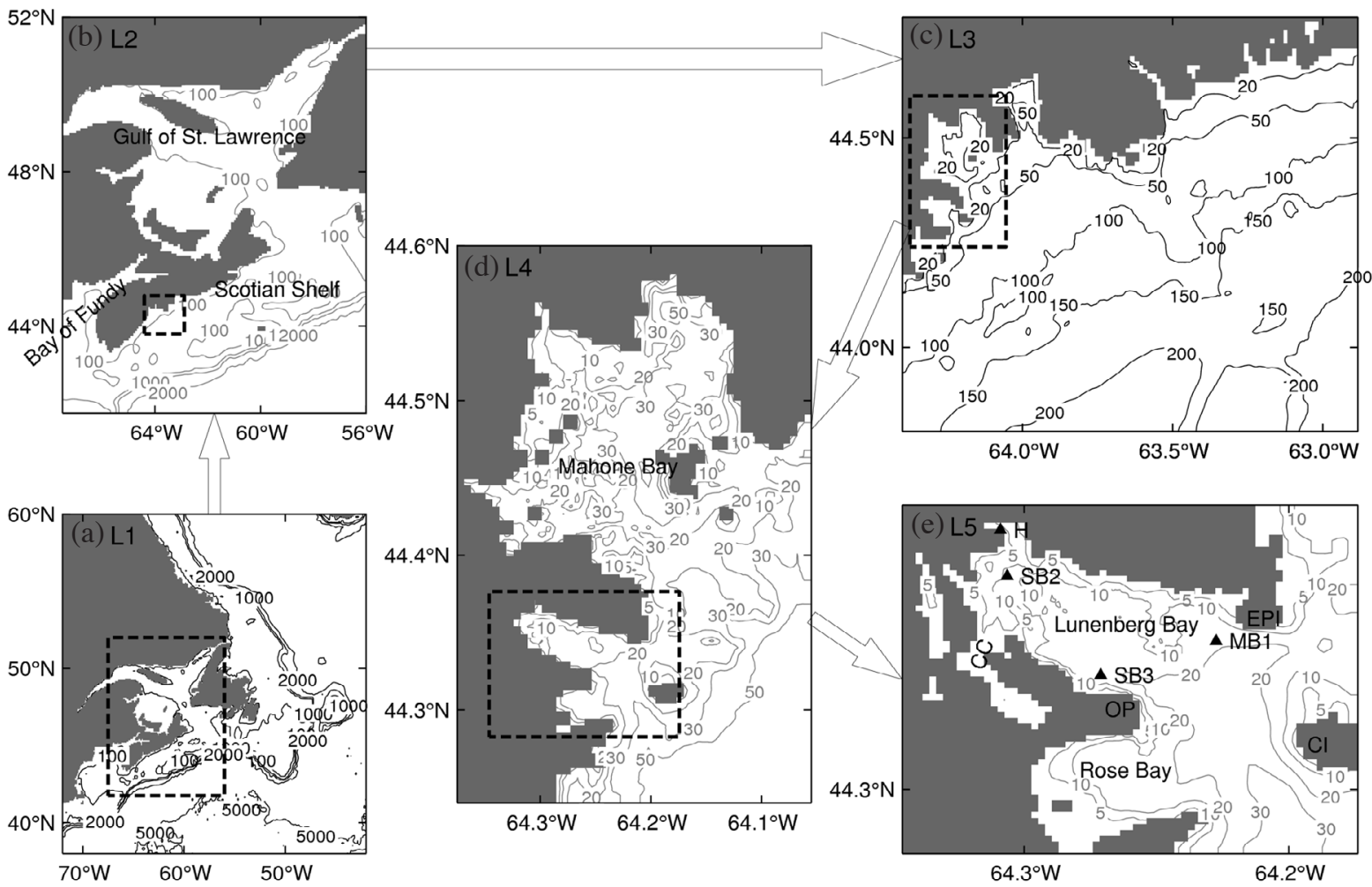

Fig. 1. Major bathymetric features of five sub-models of the nested-grid coastal ocean circulation modeling system for Canadian Atlantic coastal waters (NCOPS-LB). (a) Sub-model L1 and (b) sub-model L2 are Dalcoast3 based on POM developed by Thompson et al. (2007); (c) sub-model L3 is an intermediate resolution circulation model for the inner Scotian Shelf based on CANDIE; and (d) sub-model L4 and (e) sub-model L5 are CCMS also based on CANDIE developed by Zhai et al. (2008a). Abbreviations are used for Corkum's Channel (CC), Ovens Point (OP), East Point Island (EPI), and Cross Island (CI).

Table 1. List of model dynamics, external forcing and boundary conditions used in the five sub-components of the nested-grid modeling system. Abbreviations are open boundary conditions (OBC), two-dimensional (2D), three-dimensional (3D), tidal forcing (TF), wind forcing (WF), atmospheric pressure perturbation at the mean sea level (SLP), and surface heat and freshwater flux (SFX).

\begin{tabular}{llllll}
\hline & Sub-model 1 & Sub-model 2 & Sub-model 3 & Sub-model 4 & Sub-model 5 \\
\hline Model & POM & POM & CANDIE & CANDIE & CANDIE \\
Model Dynamics & 2D, Barotropic & 3D, Baroclinic & 3D, Baroclinic & 3D, Baroclinic & 3D, Baroclinic \\
External forcing & WF + SLP & TF + WF + SLP + SFX & TF + WF + SLP + SFX & TF + WF + SLP + SFX & TF + WF + SLP + SFX \\
OBC & Sommerfeld & $\begin{array}{l}\text { Orlanski + restoring }+ \\
\text { Davies \& Flather }\end{array}$ & $\begin{array}{l}\text { Orlanski + restoring + } \\
\text { Davies \& Flather }\end{array}$ & $\begin{array}{l}\text { Orlanski + restoring + } \\
\text { Davies \& Flather }\end{array}$ & $\begin{array}{l}\text { Orlanski + restoring + } \\
\text { Davies \& Flather }\end{array}$ \\
\hline
\end{tabular}

sea surface temperature $\left(S S T_{m}\right)$ and the observed sea surface temperature $\left(S S T_{o}\right)$ at $\mathrm{SB} 3$ in LB. The additional net heat flux in sub-models L4 and L5 is then diagnosed based on

$\hat{Q}=\frac{\Delta z}{\rho_{0} C_{p}} \frac{\partial}{\partial t}\left(S S T_{o}-S S T_{m}\right)$

where $\rho_{0}$ is the water density and $C_{p}$ is heat capacity of sea water (Sheng and Yang 2008). Similarly, the net freshwater flux at the sea surface in sub-models L4 and L5 (Fig. 2e) is diagnosed based on

$$
E-P=\frac{\Delta z}{S S S_{o}} \frac{\partial}{\partial t}\left(S S S_{0}-S S S_{m}\right)
$$

where $S_{S S}$ is the observed sea surface salinity at SB3, and $S S S_{m}$ is the corresponding model sea surface salinity produced by the NCOPS-LB using all the external forcing ex- 
cept for zero sea surface freshwater flux. It should be noted that $S S T_{m}$ and $S S S_{m}$ in Eqs. (2) and (3) were the modeled sea surface temperature and salinity in a separate model run in which the additional net sea surface heat and freshwater fluxes shown in these two equations were set to zero.

The tidal forcing used this study is tidal elevations and depth-mean currents produced by WebTide (Dupont et al. 2002) specified at open boundaries of sub-model L2 using the open boundary condition of Davies and Flather (1978). WebTide is a tidal prediction program developed at the Bedford Institute of Oceanography (BIO) based upon five major pre-calculated tidal harmonic constituents $\left(\mathrm{M}_{2}, \mathrm{~N}_{2}\right.$,
$\mathrm{S}_{2}, \mathrm{~K}_{1}$, and $\mathrm{O}_{1}$ ) for the ECS estimated from previous tidal ocean model results (Dupont et al. 2002).

The model boundary conditions used in the NCOPSLB (Sheng and Yang 2008) are described as follows. At lateral solid boundaries of each sub-model, the normal flow, tangential stress of the currents and normal fluxes of temperature and salinity are set to zero. Along the open boundaries of sub-model L1 (Fig. 1a, Table 1), the Sommerfeld radiation condition (Chapman 1985) is used for sea surface elevations and depth-mean currents (since sub-model L1 is a two-dimensional, depth-averaged storm surge model). Along the open boundaries of sub-model L2 (Fig. 1b),
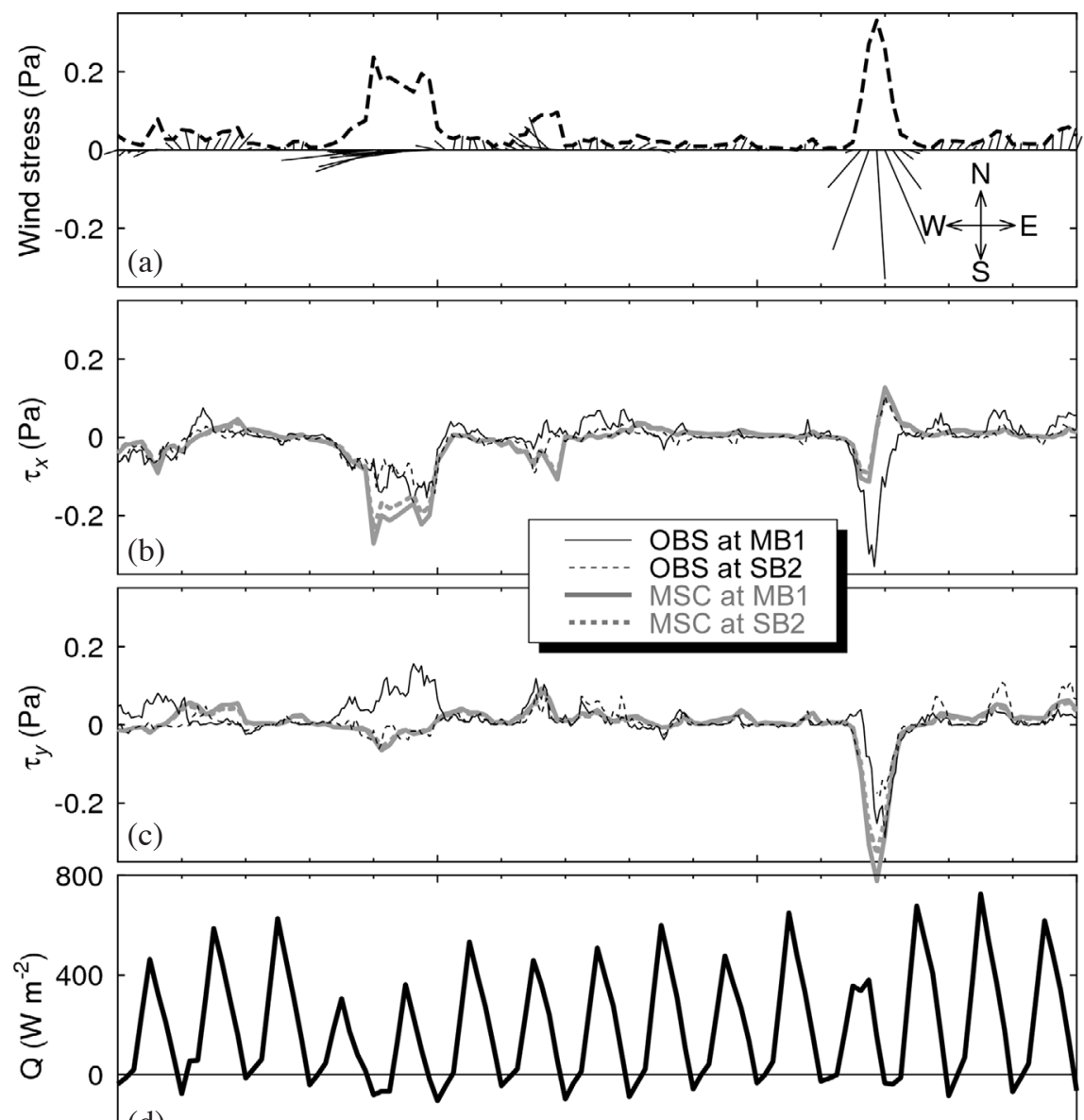

(d)

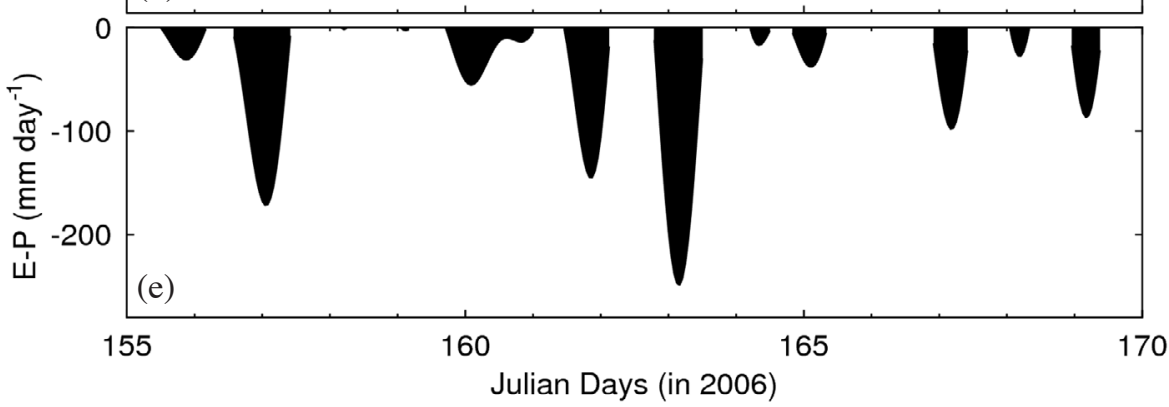

Fig. 2. Time series of (a) the stick plot of wind stress, (b) the eastward and (c) northward components of observed and MSC wind stress, (d) the net sea surface heat flux at SB2, and (e) the diagnosed net sea surface freshwater flux from day 155 to 170 in 2006 . The dashed line in (a) represents the amplitude of wind stress. 
the model surface elevation and depth-mean currents are restored to a combination of the sea surface elevations and depth-mean currents produced by sub-model L1 (meteorologically forced) and those produced by WebTide (tidally forced) with a restoring time scale of 1 hour (Table 1). Model temperature and salinity along the open boundaries of sub-model L2 are advected outward if the normal flow at the open boundaries is outward and nudged to the seasonal mean, spatially and vertically varying climatology if the model flow is inward (Ohashi et al. 2009). For sub-models L3 - L5 based on CANDIE (Figs. 1c - e), the following oneway nesting technique is used for specifying open boundary conditions (Table 1). The Orlanski (1976) radiation condition is first used to determine whether the open boundary is passive or active. If the open boundary is passive, the model variables (including model temperature, salinity and threedimensional baroclinic currents, Marchesiello et al. 2001; Wang et al. 2009) along the open boundaries are restored to the interpolated fields from model results produced by the upper-level sub-component, with a restoring time scale of $\sim 1$ hour. If the open boundary is active, the model variables at the open boundaries are advected outward. An additional adjustment is made to the depth-mean currents along the open boundaries based on the open boundary condition of Davies and Flather (1978) to allow the proper propagation of (barotropic) tidal forcing and meteorologically forced surface elevations and depth-mean currents produced by sub-model L1 from the open boundaries of sub-model L2 to lower-level sub-models.

It should be noted that additional correction terms expressed in terms of restoring boundary conditions to seasonal mean hydrographic climatology are added to the net sea surface heat and freshwater fluxes in sub-model L2 using the spectral nudging approach (Thompson et al. 2007) to reduce the model drift. The spectral nudging technique restores the model temperature and salinity to their respective climatologies only at specific frequencies that are relevant to the climatologies (the mean, the annual cycle and its harmonics in this study). At frequencies other than these specific frequencies, the model is effectively prognostic. Readers are referred to Thompson et al. (2007) and Ohashi et al. (2009) for more discussion on the correction terms and the spectral nudging approach.

\section{STORM-INDUCED CIRCULATION DURING TROPICAL STORM ALBERTO}

The nested-grid modeling system (NCOPS-LB) is used to simulate the 3D circulation and hydrographic distributions over the coastal waters of the Scotian Shelf in June 2006, with a special emphasis on the storm-induced circulation during tropical storm Alberto. The NCOPS-LB is initialized from (horizontally and vertically varying) seasonal mean hydrographic climatology (constructed by Geshelin et al. 1999) on April 1 (Day 121), 2006 and integrated for 3 months using all the external forcing discussed in section 2. The model results during a 20-day period from day 155 to 175 are presented in this paper, except where otherwise stated. During this study period, there were two storm events that significantly affected the circulation over the inner Scotian Shelf. Figure 2 shows time series of wind stress and net sea surface heat and freshwater fluxes calculated from the MSC forecast products at site SB2 in LB (Fig. 1e) from day 155 to 175 in 2006. The MSC wind stress in LB (Fig. 2) was relatively weak $(\sim 0.05 \mathrm{~Pa})$ and roughly northward during this study period, except for two storm events. The first storm event occurred from day 158 to 160 with a maximum wind stress of $\sim 0.2 \mathrm{~Pa}$ associated with a low pressure system moving northward over the eastern Gulf of Maine (GOM). The second event occurred on days 166 and 167 with a maximum wind stress of $\sim 0.3 \mathrm{~Pa}$ associated with tropical storm Alberto moving northeastward over the central Scotian Shelf (Fig. 3). In comparison of wind stress converted from observed winds at mooring sites SB2 and MB1 in LB, the MSC wind stress is in good agreement with the observations, with some noticeable differences during the two storms.

Tropical storm Alberto formed on 10 June 2006 as a tropical depression in the northwestern Caribbean Sea (www.nhc.noaa.gov). Alberto moved northwestward to the southeastern Gulf of Mexico and became a tropical storm on June 11 with a peak intensity of about $110 \mathrm{~km} \mathrm{~h}^{-1}$. The storm emerged off the mid-Atlantic coast of the United States on June 14 and accelerated northeastward to the Canadian Atlantic provinces (Fig. 3). The storm deepened into a powerful post-tropical storm as it swept the Scotian Shelf on June 15 with a maximum peak wind of about $100 \mathrm{~km} \mathrm{~h}^{-1}$. Figure 4 shows the MSC sea level atmospheric pressure and wind stress fields over the GSL-Scotian Shelf region during the storm. At day 166.75 (1800 UTC 15 June), the storm center was located at the southern Scotian Shelf with a maximum wind stress of $\sim 1.5 \mathrm{~Pa}$ (Fig. 4a), and the wind stress was southwestward over the inner Scotian Shelf (Fig. 2a). At day 167.0 (0000 UTC 16 June), the storm center approached the central Scotian Shelf with a maximum wind stress of $\sim 2.0 \mathrm{~Pa}$ on the right hand side of the track (Fig. 4b), and the wind stress was roughly onshore over the eastern Scotian Shelf and offshore over the western Scotian Shelf. The storm center moved to the northeastern shelf at day 167.25 (0600 UTC 16 June) with a maximum wind stress of $\sim 1.0 \mathrm{~Pa}$ (Fig. 4c), and the wind stress in LB at this time was relatively weak and roughly eastward (Fig. 2a). The storm reached the western Grand Banks (GB) and made landfall over southern Newfoundland at noon on June 16 with a maximum wind stress of $\sim 0.8 \mathrm{~Pa}$ (Fig. 4d).

The six-hourly positions of the "best storm track" of Alberto produced by the Canadian Hurricane Center (CHC) (www.atl.ec.gc.ca/wether/hurricane/images) were also plot- 
ted in Fig. 4. The "best track" of the storm was constructed from multi-source measurements and can be used to validate the performance of the MSC numerical weather model in predicting the center position of the storm. At days 166.75 and 167.50 (Figs. 4a and d), the MSC numerical weather forecast model reproduces reasonably well the storm centers. By comparison, there are noticeable differences between the storm centers produced by the MSC numerical forecast model and the $\mathrm{CHC}$ best storm track from day 167.00 to 167.25, which explain large differences between the MSC forecast winds and the observed winds in LB shown in Figs. 2b and c. The less accurate MSC wind forcing will affect the performance of the NOCPS-LB during this period to be discussed in section 4 .

Figure 5 shows the simulated sea surface elevations, depth-mean currents, surface (or near-surface) temperatures and currents produced by the NCOPS-LB at 1800 UTC 15 June 2006 (day 166.75). The center of the storm is located at the southwestern Scotian Shelf at this time (Fig. 5a). The simulated total sea surface elevations (i.e., the sum of the adjusted sea level and isostatic sea level due to the inverse barometer effect, Gill 1982) at day 166.75 produced by sub-model L1 are positive over the ECS (in the barotropic response of the ECS to the wind forcing and sea level atmospheric pressure perturbations), with a maximum value of $\sim 50 \mathrm{~cm}$ near the storm center on the southern Scotian Shelf due mainly to the large inverse barometer effect associated with the lower atmospheric pressure at the center of the storm (Fig. 5a). Sub-model L1 also generates relatively large depth-mean currents over the shallow water regions of the ECS, and very strong southwestward currents over the coastal region of the western Scotian Shelf at day 166.75 (Fig. 5a).

The simulated surface currents over the GSL-Scotian Shelf region at day 166.75 produced by sub-model L2 are characterized by a large-scale cyclonic recirculation over the Scotian Shelf and southwestern GSL and relatively weak surface currents over the eastern Scotian Shelf and central GSL (Fig. 5b). The simulated SSTs at this time are relatively cool and $\sim 8^{\circ} \mathrm{C}$ on the Scotian Shelf and the northern and eastern GSL and relatively warm and $\sim 12^{\circ} \mathrm{C}$ over the southwestern GSL and deep waters off the Scotian Shelf.

The simulated near-surface (at a depth of $1.5 \mathrm{~m}$ from the mean sea level) currents on the coastal waters of the central Scotian Shelf produced by sub-model L3 at 1800 UTC 15 June 2006 are relatively uniform and nearly southwestward with a typical speed of $\sim 50 \mathrm{~cm} \mathrm{~s}^{-1}$ (Fig. 5c). The simulated near-surface temperatures are about $8^{\circ} \mathrm{C}$ over the inner Scotian Shelf except for relatively warmer and $\sim 12^{\circ} \mathrm{C}$ near the coast.

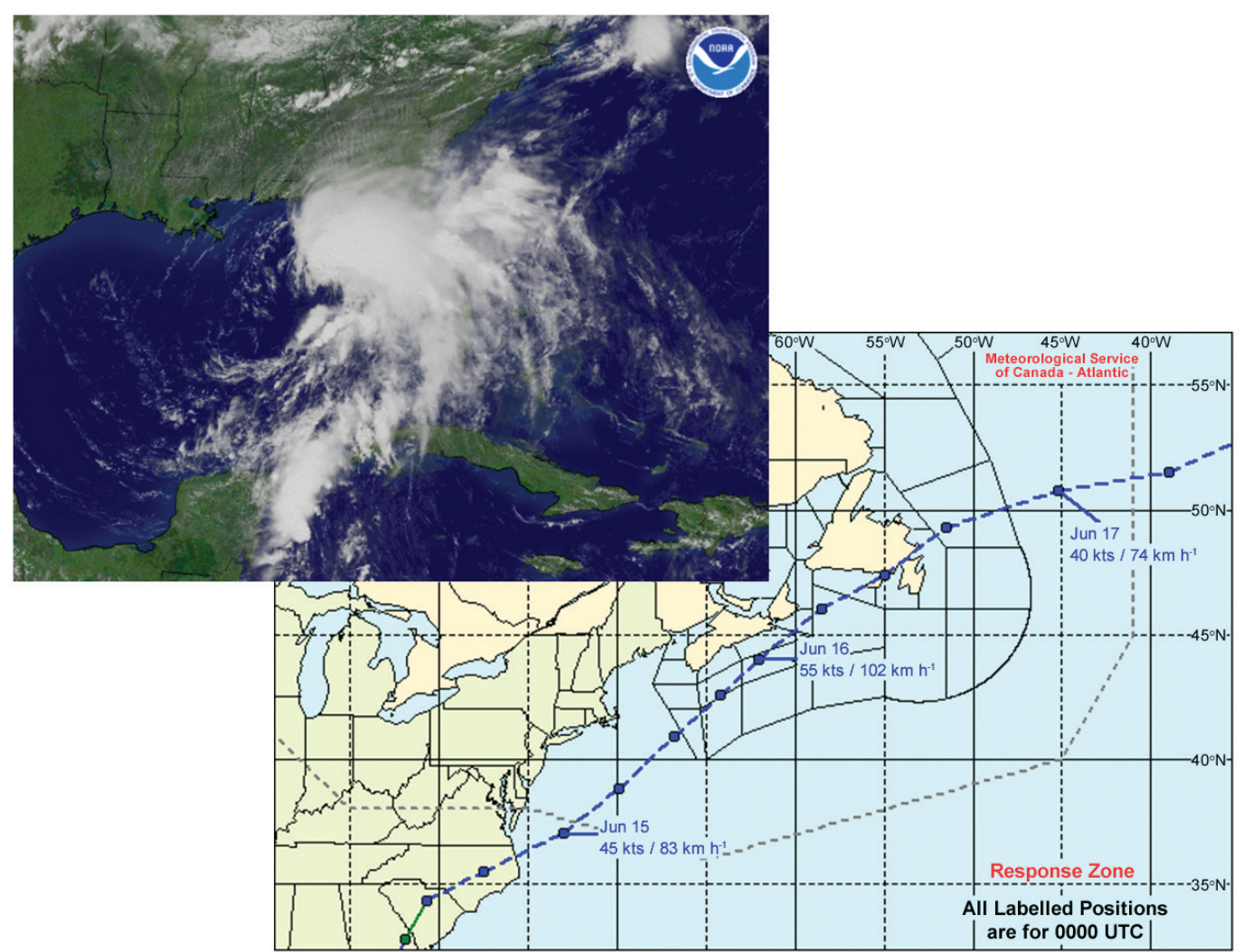

Fig. 3. Cloud image and storm track of tropical storm Alberto in June 2006 (Courtesy of the National Oceanic and Atmospheric Administration and Canadian Hurricane Centre). 
Over the 3-bay region (i.e., Mahone, Lunenburg and Rose Bays), the simulated near-surface currents produced by sub-model L4 (Fig. 5d) are nearly southwestward, which are relatively stronger over outer Mahone Bay and outer Lunenburg Bay and adjacent offshore regions and relatively weaker over inner Lunenburg Bay and inner Mahone Bay. The simulated near-surface temperatures produced by submodel L4 are about $12^{\circ} \mathrm{C}$ over inner Mahone Bay and inner Lunenburg Bay and relatively cooler and about $8^{\circ} \mathrm{C}$ over the offshore region of the three bays.

The simulated near-surface (at a depth of $1.5 \mathrm{~m}$ ) currents in LB and adjacent areas produced by sub-model L5 at day 166.75 (Fig. 5e) are characterized by an intense southwestward throughflow of $\sim 50 \mathrm{~cm} \mathrm{~s}^{-1}$ in the offshore deep waters off LB and relatively weak and southwestward currents inside LB. There is a strong northeastward jet through Corkum's Channel due mainly to the tidal circulation through the channel. The simulated near-surface (at a depth of $1.5 \mathrm{~m}$ ) temperatures produced by sub-model L5 at this time are relatively warmer and about $12^{\circ} \mathrm{C}$ over the western and northern parts of LB and relatively cooler in the deep water region off LB. There are several small-size pools of cool surface waters over the northeastern LB due to localized wind-driven upwelling.
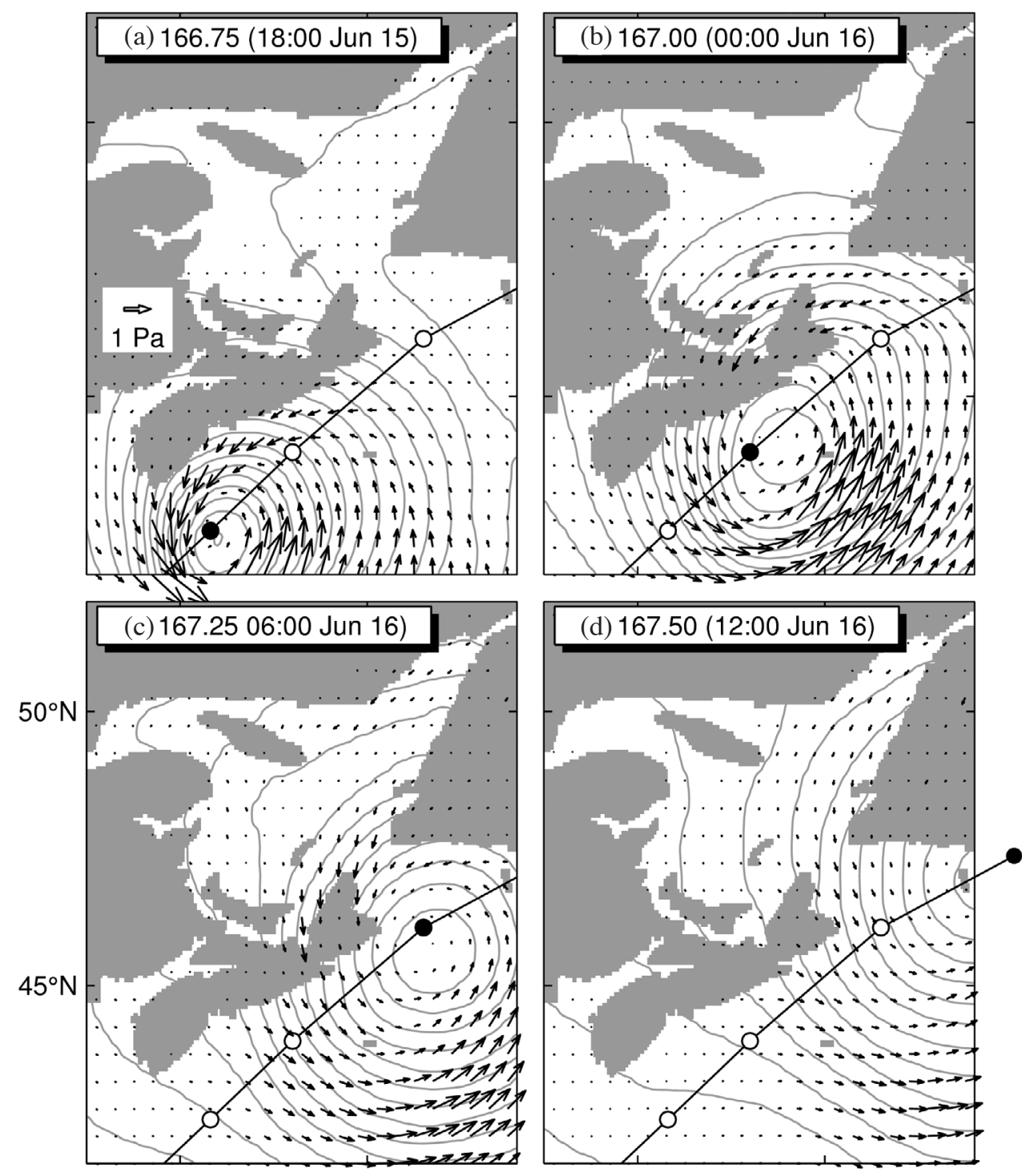

$65^{\circ} \mathrm{W}$

$60^{\circ} \mathrm{W}$

Fig. 4. Sea level atmospheric pressure and wind stress over the Scotian Shelf and Gulf of St. Lawrence during tropical storm Alberto, extracted (or calculated) from the three-hourly numerical weather forecasts fields produced by the Meteorological Service of Canada (MSC) at: (a) day 166.75 (1800 UTC 15 June), (b) day 167.00 (0000 UTC 16 June), (c) day 167.25 (0600 UTC 16 June), and (d) day 167.50 (1200 UTC 16 June) of 2006. Wind stress vectors are plotted at every second model grid point of the MSC numerical weather model. The contour interval for the sea level atmospheric pressure is $2 \mathrm{hPa}$. The solid (open) circle in represent the current (non-current) position of the 6-hourly "best track" of tropical storm Alberto produced by the Canadian Hurricane Center (www.atl.ec.gc.ca/wether/hurricane/images). 


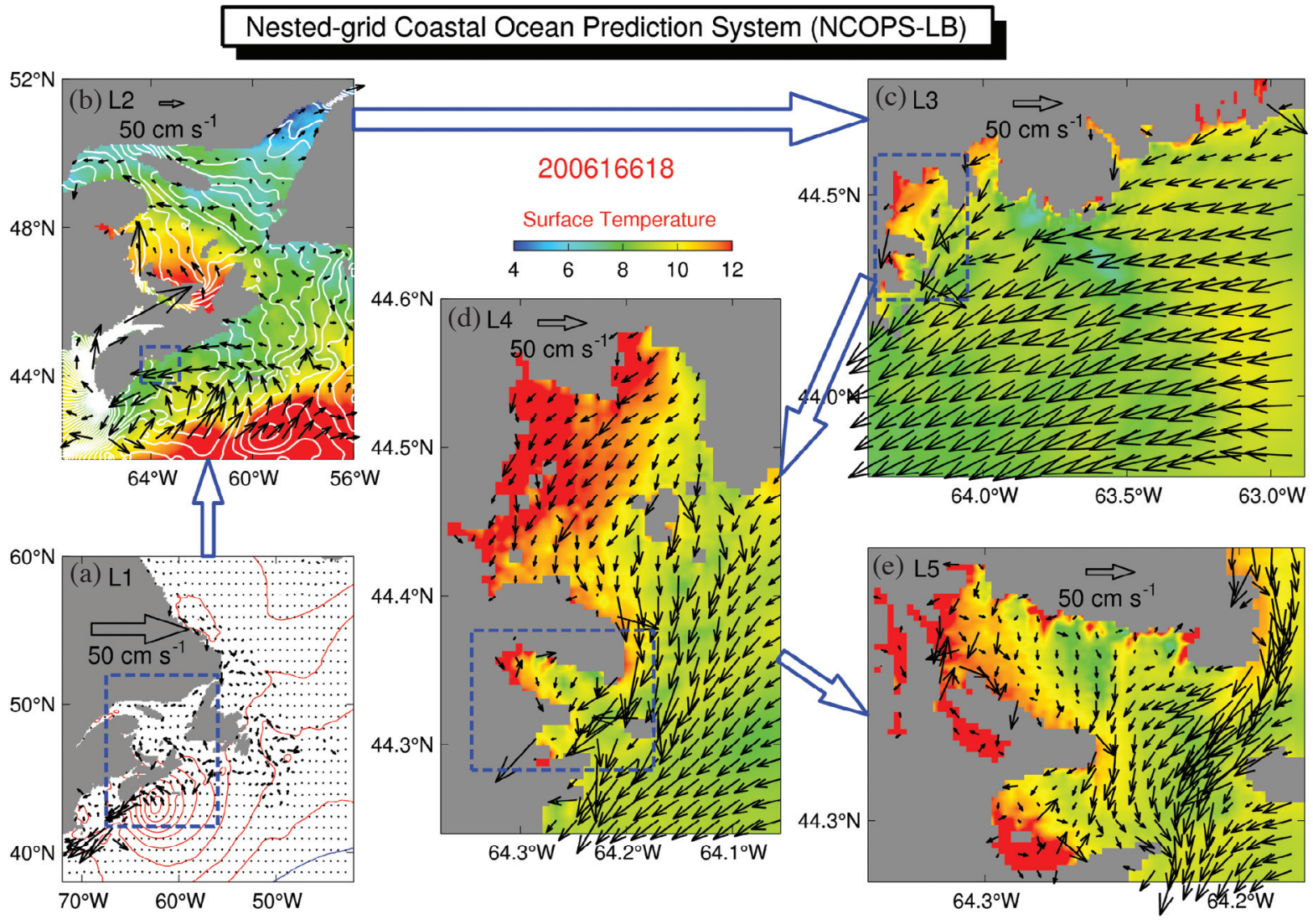

Fig. 5. (a) Simulated depth-mean currents (black arrows) and total surface elevations (red/blue contours for positive/negative values with the contour interval of $5 \mathrm{~cm}$ ) produced by sub-model L1; (b) surface currents (black arrows) and sea surface temperatures (images) produced by sub-model L2; and (c) - (e) near-surface $(1.5 \mathrm{~m})$ currents and temperature produced by sub-models L3 - L5 of the NCOPS-LB at 1800 UTC 15 June (day 166.75 ) 2006. The center of the storm at this time was located over the central Scotian Shelf. For clarity, velocity vectors are plotted at every (a) $9^{\text {th }}$, (b) $10^{\text {th }}$, (c) $4^{\text {th }}$, (d) $3^{\text {rd }}$, and (e) $2^{\text {nd }}$ model grid point.

At 1200 UTC 16 June 2007 (day 167.5), the center of the storm moved onto the Newfoundland Shelf (NF). The simulated total surface elevations at this time in the barotropic response to wind and atmospheric pressure perturbations produced by sub-model L1 (Fig. 6a) have a maximum value of about $30 \mathrm{~cm}$ over the inshore region of the Scotian Shelf; about 10 to $20 \mathrm{~cm}$ over the GB and eastern Scotian Shelf and southern GSL; and relatively small over other regions of the ECS. There are relatively large depth-mean currents at this time over the GB, southern GSL and inshore region of the Scotian Shelf and are associated mainly with the propagation of the barotropic shelf waves excited by Alberto.

Sub-model L2 generates strong and southward surface flows over the western GB, the southern GSL and the eastern Scotian Shelf and strong southwestern tidal currents in the Bay of Fundy at day 167.5 (Fig. 6b). The simulated SSTs produced by sub-model L2 at this time are relatively cool and $\sim 7^{\circ} \mathrm{C}$ over the eastern Scotian Shelf and the northern and eastern GSL, and relatively warmer and $\sim 11^{\circ} \mathrm{C}$ over the southwestern GSL and deep waters off the Scotian Shelf.
The near-surface currents produced by sub-model L3 at day 167.5 (Fig. 6c) are relatively weaker over the inner Scotian Shelf with more small-scale features except for some large currents over isolated coastal areas, in comparison with those on the previous day. The simulated near-surface temperatures are relatively warmer and about $9^{\circ} \mathrm{C}$ over the eastern part and about 7 to $8^{\circ} \mathrm{C}$ over the western part of the inner Scotian Shelf. Over the 3-bay region (Fig. 6d), the simulated near-surface currents are roughly northwestward over outer Mahone Bay and relatively weak over inner Mahone Bay and inside Lunenburg and Rose Bays. The simulated near-surface temperatures are about $10{ }^{\circ} \mathrm{C}$ in the 3-bay region at this time.

The simulated near-surface currents produced by sub-model L 5 at 1200 UTC 16 June are characterized by relatively weak currents over central and inner Lunenburg and Rose Bay; a strong southwestern jet through Corkum's Channel and northwestward jet through the narrow mouth between Upper and Lower South Coves is due mainly to the tides (Fig. 6e). The simulated near-surface temperatures are 


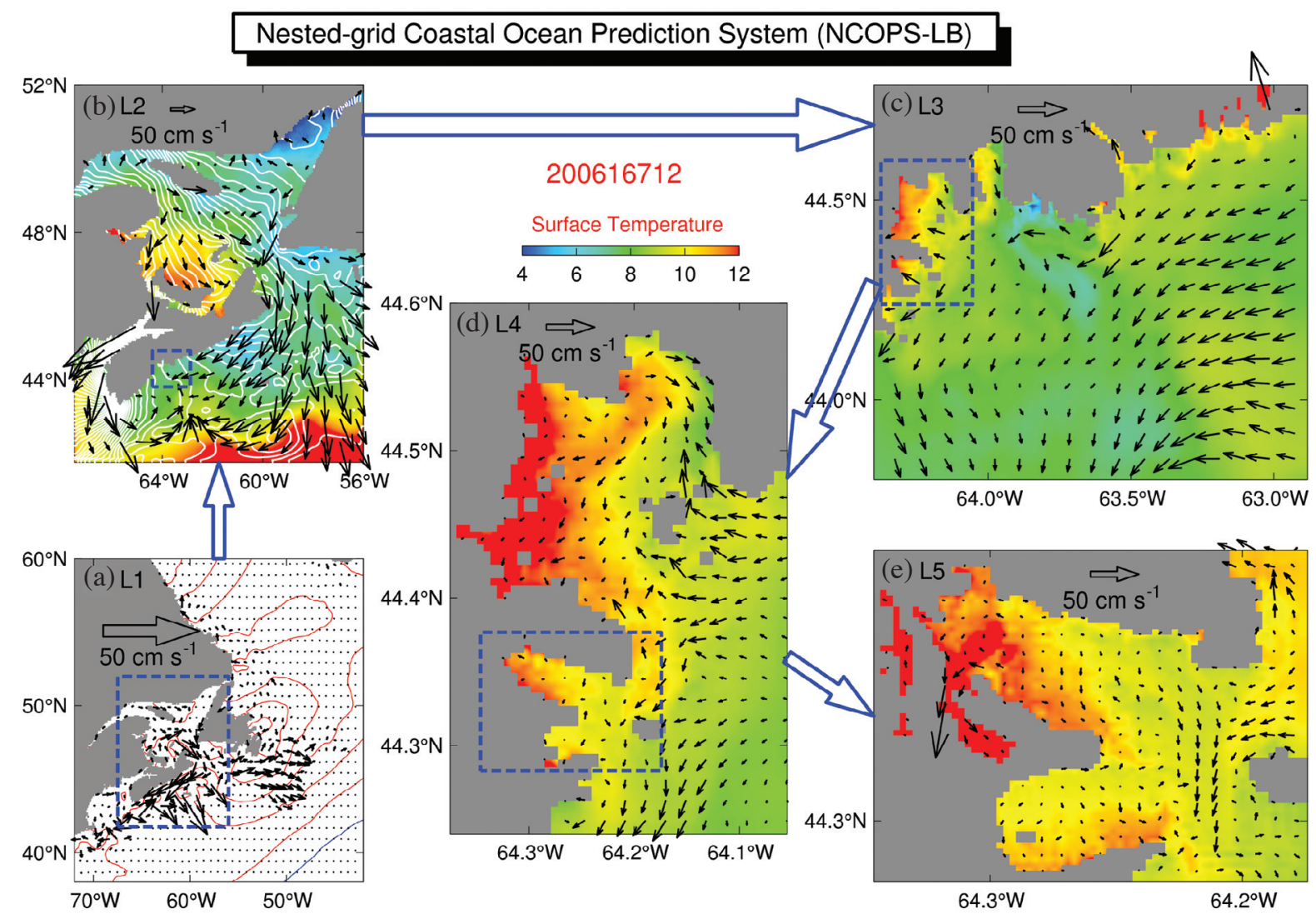

Fig. 6. (a) Simulated depth-mean currents (black arrows) and total surface elevations (red/blue contours for positive/negative values with the contour interval of $5 \mathrm{~cm}$ ) produced by sub-model L1; (b) surface currents (black arrows) and sea surface temperatures (images) produced by sub-model L2; and (c) - (e) near-surface $(1.5 \mathrm{~m})$ currents and temperature produced by sub-models L3 - L5 of the NCOPS-LB at 1200 UTC 16 June (day 1675 ) 2006. The center of the storm at this time was located over the inshore region of the Newfoundland Shelf. For clarity, velocity vectors are plotted at every (a) $9^{\text {th }}$, (b) $10^{\text {th }}$, (c) $4^{\text {th }}$, (d) $3^{\text {rd }}$, and (e) $2^{\text {nd }}$ model grid point.

relatively warmer over Rose Bay and western and northern Lunenburg and relatively cooler over the southeastern LB and deep waters to the south of Cross Island (CI).

\section{ASSESSING THE PERFORMANCE OF THE NESTED-GRID SYSTEM}

The simulated surface elevations and currents produced by sub-model L5 of the NCOPS-LB are compared with the observations made by a multidisciplinary ocean observation system in LB to assess the hindcast skill of the nested-grid modeling system. The ocean observation system is part of CMEP-Bay and was established in summer 2002 and had been operational from spring to fall over a 7 -year period from 2002 to 2008 . The core of the observation system consists of three solar-powered buoy nodes in central LB wherein the locations are marked by SB2, SB3, and MB1 in Fig. 1e. Each buoy-node communicated wirelessly with the shore station at Battery Point. Subsequently, the data were transferred to Dalhousie University in Hali- fax over the internet in near-real time. Each buoy node had a suite of oceanographic and meteorological sensors. The sensors on each buoy node relevant to this study included a pressure gauge and an upward-looking 1.5-MHz Sontek Acoustic Doppler profiler (ADP), both deployed on a bottom-mounted pod connected to the buoy by a power and communications cable. An anemometer was mounted on each buoy at 3-m height. In addition to the buoy nodes, a bottom-mounted pressure-temperature sensor was also deployed at site $\mathrm{H}$ inside Lunenburg Harbor during the study period. Readers are referred to Wang et al. (2007) for a more detailed description of the ocean observing system in the bay.

The hindcast skill of the NCOPS-LB in simulating the temporal variability is quantified in terms of the $\gamma^{2}$ values defined as (Thompson and Sheng 1997):

$\gamma^{2}=\operatorname{Var}(M-O) / \operatorname{Var}(O)$

where $M$ and $O$ represent respectively the model-calculated 
and observed variables, and Var represents the variance. Physically, the $\gamma^{2}$ value is the variance of the model errors normalized by the observed variance. The smaller $\gamma^{2}$ is, the better the agreement between the model and observations. In this paper $\gamma_{c}^{2}=1$ is used as a threshold for assessing the performance of the nest-grid system. It should be noted that the $\gamma^{2}$ value is very similar to, but more conservative than, the cross-correlation coefficient. This can easily be demonstrated by considering a case in which the observed and simulated time series are the same sinusoidal function but with different amplitudes of $A_{o}$ and $A_{s}$ respectively. The cross-correlation coefficient in this case is equal to 1 , while the $\gamma^{2}$ value is equal to $\left(1-A_{s} / A_{o}\right)^{2}$ and greater than zero if $A_{o}$ and $A_{s}$ are not the same. It should be noted that the predictive skill used by Wilmott (1981) and Warner et al. (2005) is equal to $\left(1-\gamma^{2}\right)$.

\subsection{Sea Surface Elevations}

Figure 7 presents time series of observed and simulated (adjusted) sea surface elevations at three sites MB1, SB2, and $\mathrm{H}$ in LB during a 20-day period from day 155 to 175 in 2006. Tidal harmonic analysis using T_TIDE (Pawlowiz et al. 2002) demonstrates that the observed sea surface elevations in $\mathrm{LB}$ are dominated by the semidiurnal tide $\mathrm{M}_{2}$, which is consistent with previous studies (Thompson et al. 1998; Sheng and Wang 2004; Wang et al. 2007). The $\gamma^{2}$-values between the predicted and observed (adjusted) sea surface elevations at these three sites are very small and about 0.06 , indicating that the NCOPS-LB performs very well in reconstructing the observed surface elevations in the bay.

Two storm events affected the circulation over the coastal waters of the inner Scotian Shelf during this 20day period. To assess the model performance in simulating the wind-driven sea surface elevations in LB, the non-tidal sea surface elevations were extracted from the adjusted sea surface elevations by removing tidal components using T_TIDE and a low pass filter with a cut-off period of $25 \mathrm{~h}$ to eliminate any additional tidal components. Figure 8 shows the observed and simulated non-tidal surface elevations during the 20-day period. The temporal variabilities of the observed non-tidal surface elevations at the three sites in LB were similar and nearly in phase during this period, which are characterized by a (non-tidal) sea level rise from a small value on day 158 to reach a maximum setup of $\sim 12 \mathrm{~cm}$ on day 159 associated with the first storm event, a gradual fall after reaching the maximum to day 164; and high-frequency, small-amplitude variations around day 166 associated the second storm event. The main reason for a relatively larger sea level setup in LB during the first storm than that during Alberto is that the wind stress was mainly southwestward and alongshore during the first storm and mainly southward and offshore during Alberto (Fig. 4a). In terms of weather dynamics, alongshore wind forcing gener- ates much larger coastal setup/setdown than the cross-shore wind forcing with the same amplitude. The alongshore and on/offshore directions used here are defined in terms of the southern coastline of Nova Scotia.

Figure 8 demonstrates that sub-model L5 of the NCOPS-LB reproduces the observed non-tidal sea level variations at the three sites in LB during the first storm reasonably well, but less well during Alberto. Although the exact reason is unknown why the NCOPS-LB performs less well in simulating the non-tidal surface elevations during the storm, the most possible explanation is that the MSC wind forcing is less accurate during the second storm as shown in Figs. $2 b$ and c. The $\gamma^{2}$ values for the observed and predicted non-tidal sea levels during this period are $\sim 0.57$ at MB1, 0.48 at SB2 and 0.46 at $\mathrm{H}$ in LB which are larger than the values for the total sea levels shown in Fig. 7 but still smaller than the threshold value indicating the NCOPS-LB also has reasonable skills in hindcasting the non-tidal sea level variations during this period.

\subsection{Currents}

Figure 9 presents the observed and simulated currents at three depths of $4.5,6.5$, and $8.5 \mathrm{~m}$ at buoy nodes SB2, SB3, and MB1 in LB during the 20-day study period. The observed currents are extracted from the ADCP measurements and the simulated currents are produced by sub-model L5 of the NCOPS-LB. The observed currents in LB have significant temporal and spatial variabilities with relatively stronger flows at SB3 and MB1 and weaker flows at SB2. Sub-model L5 reproduces the temporal variability and vertical structures of the eastward components of the observed currents at SB2, with the $\gamma^{2}$ values between 0.48 and 0.54 (Figs. 9a - c) reasonably well. In comparison, sub-model L5 performs less well in simulating the northward components of the observed currents at the three depths at site SB2 particularly during the two storms, with the $\gamma^{2}$ values ranging between 0.97 and 1.32 (Figs. 9j - 1). Although exact reasons are not known for the model deficiency in simulating the northward components of the currents at SB2, the currents at this site are affected significantly by an intense tidal jet running northeastward from Corkum's Channel to inner LB (Sheng and Wang 2004; Wang et al. 2007) which is highly nonlinear and could not easily be simulated by sub-model L5 with the horizontal resolution of about $180 \mathrm{~m}$. At site SB3, the observed currents had relatively stronger tidal currents in the eastward direction (Figs. 9d - f) than in the northward direction (Figs. 9m - o, which is consistent with the general orientation of the local bathymetry to be nearly east-west at this site (Fig. 1e). Sub-model L5 simulates the observed currents at SB3 reasonably well in the eastward (or alongshore) direction with $\gamma^{2}$ values to be $0.51-0.64$, but less well in the northward (or offshore) direction with $\gamma^{2}$ values to be $0.76-0.99$. It is a common problem for numeri- 


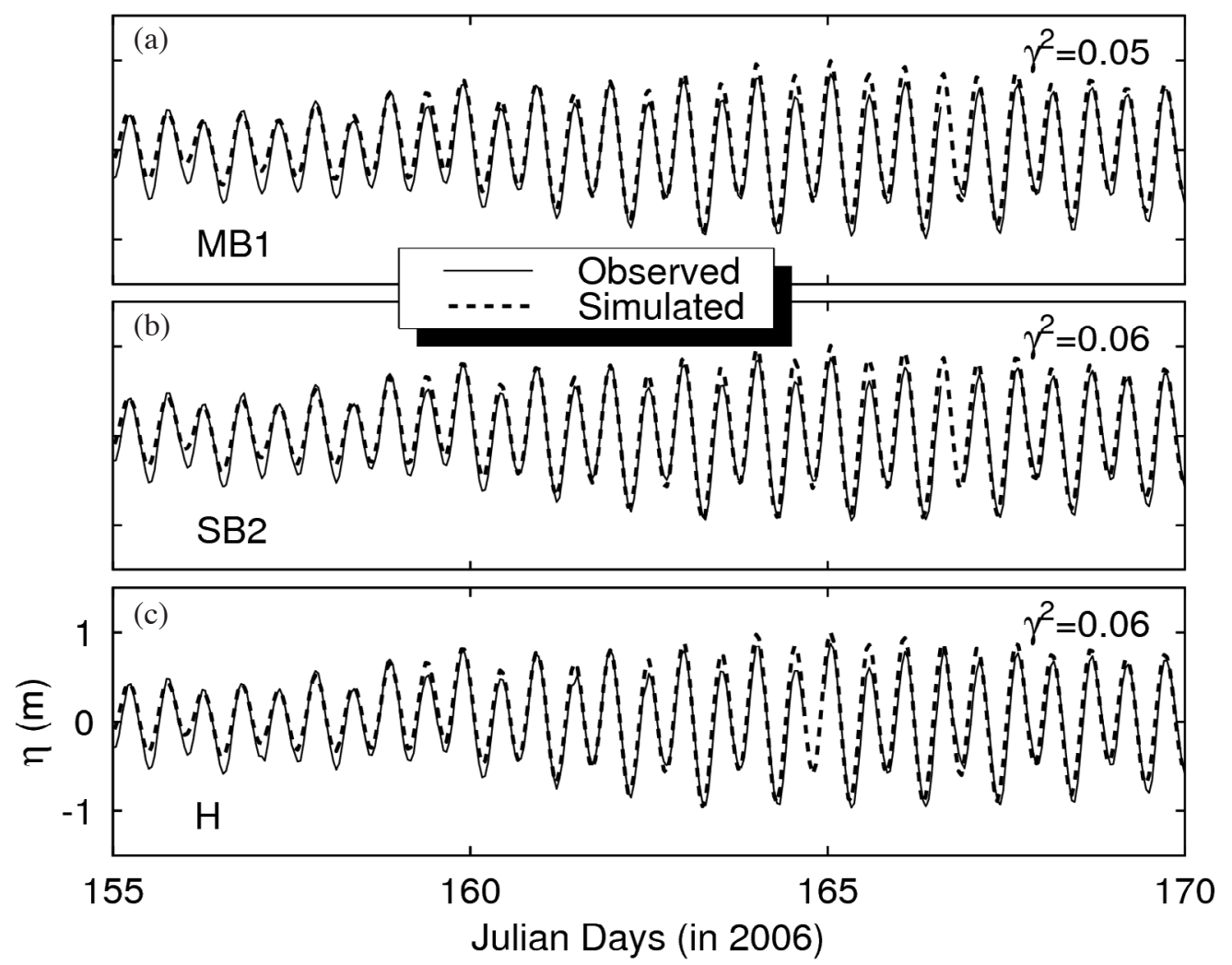

Fig. 7. Comparison of observed (solid) and simulated (dashed) adjusted sea surface elevations ( $\eta$ ) in units of meters at sites (a) MB1, (b) SB2, and (c) H. The simulated results are produced by sub-model L5 of the modeling system.

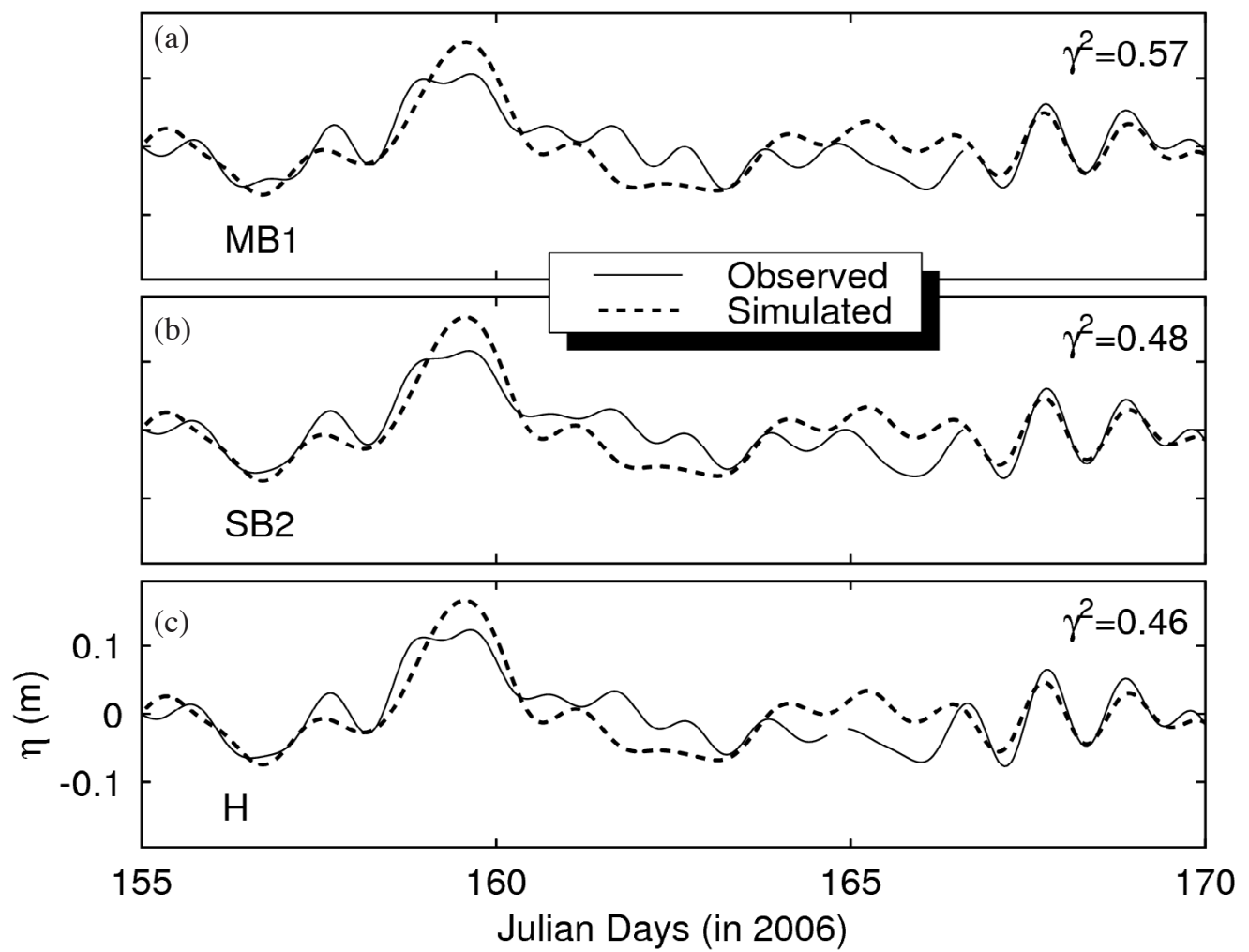

Fig. 8. Comparison of observed (solid) and simulated (dashed) non-tidal elevations ( $\eta$ ) in units of meters at sites (a) MB1, (b) SB2 and (c) H. The simulated results are produced by sub-model L5. 

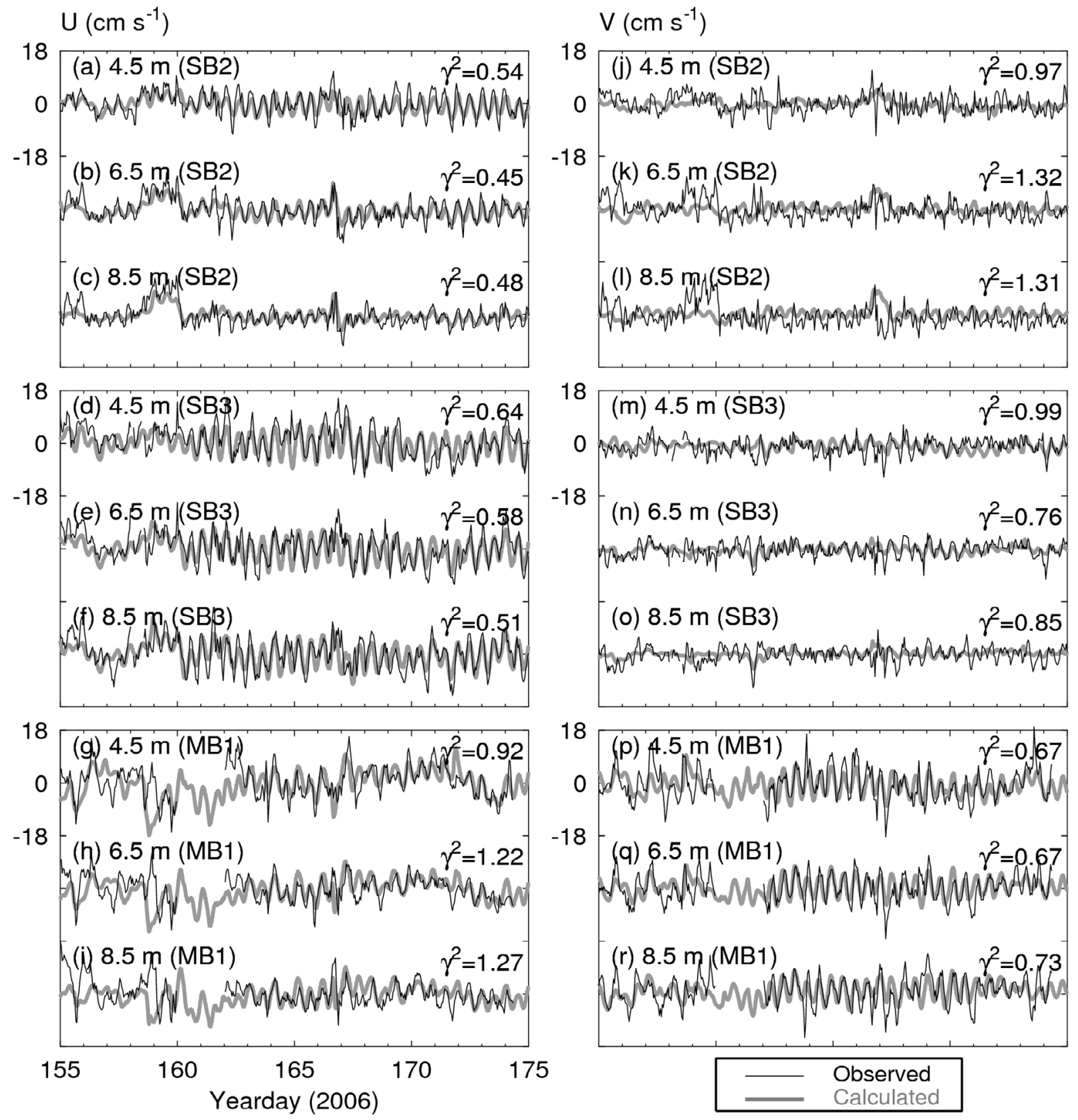

Fig. 9. Time series of (left) eastward and (right) northward components of observed (thin black) and simulated (light gray) currents at depths of 4.5, 6.5, and $8.5 \mathrm{~m}$ for sites (top) SB2, (middle) SB3 and (bottom) MB1. The simulated results are produced by sub-model L5.

cal models to perform less well in resolving the offshore components than the alongshore components of observed currents over the coastal and shelf waters. At site MB1, the observed currents at three depths also had relatively strong tidal components (with a gap of missing data on days 160 and 161). Sub-model L5 has reasonable skills in simulating the northward components of the observed currents at the three depths with the $\gamma^{2}$ values between $0.67-0.73$ (Figs. 9p - r), but performs poorly in simulating the eastward components of the observed currents with the $\gamma^{2}$ values between 0.92 and 1.27 (Figs. 9g - i). In particular, the eastward components of the simulated currents at MB1 differ significantly from the observations on days 158 and 159. It is not clear whether the large differences between the observed and simulated currents at MB1 during this 2-day period are due to a deficiency of the nested-grid system or instrumental problems of the ADCP deployed at this site.

The harmonic analysis of the observed and predicted currents using T_TIDE demonstrates that the semidiurnal $\left(\mathrm{M}_{2}\right)$ tidal flow is the predominant tidal constituent in the bay, consistent with previous studies (Sheng and Wang 2004; Zhai et al. 2008a). Figure 10 shows the observed and 
simulated $\mathrm{M}_{2}$ tidal current ellipses at the three sites in LB throughout the water column. At site MB1, the observed $\mathrm{M}_{2}$ tidal currents during the study period are nearly rectilinear, with a decrease in speeds with depth from of $\sim 10 \mathrm{~cm} \mathrm{~s}^{-1}$ near surface to $\sim 5 \mathrm{~cm} \mathrm{~s}^{-1}$ near the bottom at about $13 \mathrm{~m}$. The sub-model reproduces the amplitude and orientation of the observed $\mathrm{M}_{2}$ tidal current ellipses at this site reasonably well. At site SB3, the observed $\mathrm{M}_{2}$ tidal currents are nearly rectilinear and aligned roughly with the bottom topography, with a typical speed of $\sim 10 \mathrm{~cm} \mathrm{~s}^{-1}$ at all depths. Submodel L5 reproduces the observed $\mathrm{M}_{2}$ tidal current ellipses in the top $7 \mathrm{~m}$ at this site very well. At deeper depths of greater than $8 \mathrm{~m}$ at site $\mathrm{SB} 3$, the simulated $\mathrm{M}_{2}$ tidal current ellipses have similar speeds as the observations, but have significant differences in the shape and orientation with the observed ellipses. The observed $\mathrm{M}_{2}$ tidal currents at SB2 are about $6 \mathrm{~cm} \mathrm{~s}^{-1}$ and have significant vertical variations in the shape of ellipses which due mainly to the influence of the jet-like flow in inner LB emanating from Corkum's Channel as mentioned earlier. The sub-model performs less well in reproducing the observed $\mathrm{M}_{2}$ tidal ellipses at site SB2 than at the other two sites. In particular, the submodel does not reproduce the shape and rotation direction of the observed $\mathrm{M}_{2}$ currents at SB2 very well. Sheng

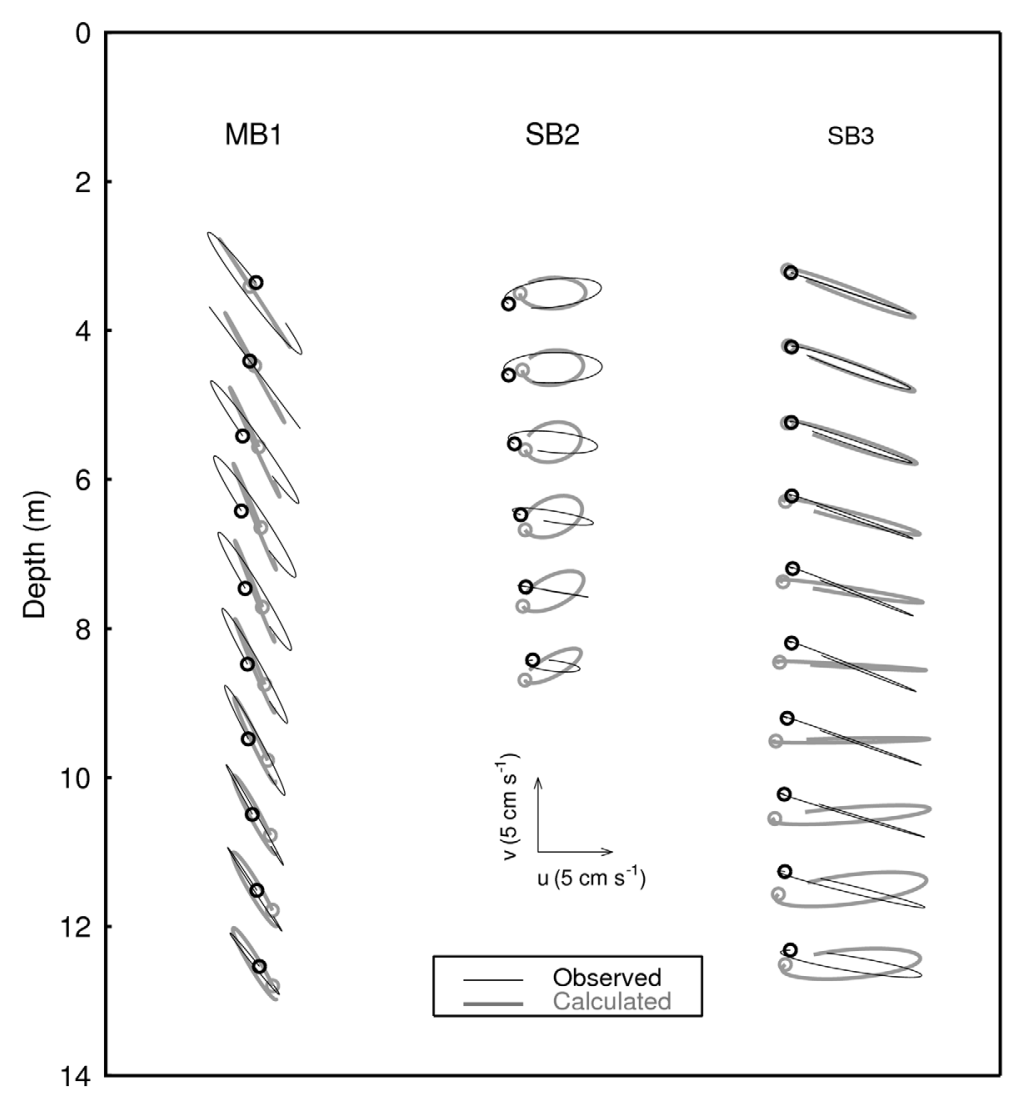

Fig. 10. Comparison of observed (thin black) and simulated (light gray) $\mathbf{M}_{2}$ tidal ellipses at different depths at sites MB1, SB2, and SB3 in Lunenburg Bay. The simulated results are produced by sub-model L5. and Wang (2004) studied the tidal circulation in LB using a tidal circulation model with a horizontal resolution of $\sim 60 \mathrm{~m}$. They demonstrated that the tidal circulation at site SB2 and vicinity is affected significantly by the tidal jet emanating from Corkim's Channel and tidal current ellipses in this area vary significantly in shape and rotation. Sub-model L5 of the NCOPS-LB has a horizontal resolution of about $\sim 180 \mathrm{~m}$, and does not resolve the tidal jet and tidal currents in the area very well.

We next assess the model performance in simulating the non-tidal currents during this study period. Figure 11 presents the observed and simulated non-tidal currents at three different depths at sites SB2, SB3, and MB1 in LB. The non-tidal currents were extracted from the total currents shown in Fig. 9 using T_TIDE and a low-pass filer with a cutoff period of 25 hours. The observed non-tidal currents are relatively weak at SB2 and relatively strong at other sites during this period. On day 159 , the observed non-tidal currents were relatively large and northeastward at $\mathrm{SB} 2$, with a maximum speed of $\sim 5 \mathrm{~cm} \mathrm{~s}^{-1}$ at $4.5 \mathrm{~m}, \sim 6 \mathrm{~cm} \mathrm{~s}^{-1}$ at $6.5 \mathrm{~m}$ and $\sim 10 \mathrm{~cm} \mathrm{~s}^{-1}$ at $8.5 \mathrm{~m}$ for both the eastward and northward components. This northeastward non-tidal flow was primarily associated with, and roughly in an opposite direction to, the southwestward wind forcing on day 159

(Fig. 2a). The relatively strong sub-surface northeastward non-tidal flow and a weaker near-surface northeastward flow indicated strong vertical shears during the first storm. The relatively large observed non-tidal currents at the three depths at three sites on days 166 and 167 are mainly associated with tropical storm Alberto. Sub-model L5 has reasonable skills in simulating the eastward components of the observed currents at SB2 associated with the two storms with the $\gamma^{2}$ values between $0.37-0.44$ (Figs. 11a - c), but less well in simulating the northward components with the $\gamma^{2}$ values between $0.63-1.21$ (Figs. $11 \mathrm{j}$ - 1). At site SB3, sub-model L5 captures the eastward components of observed non-tidal currents at three depths with the $\gamma^{2}$ values between $0.48-0.73$ (Figs. 11d - f) reasonably well, but underestimates the northward components values with the $\gamma^{2}$ values between 0.73 and 1.33 (Figs. $11 \mathrm{~m}-$ o). At MB1, sub-mode L5 performs poorly in simulating the observed non-tidal currents, particularly the eastward components (Figs. 11g - i, p - r).

\subsection{Hydrography}

Figures 12 and 13 demonstrate a comparison of simulated SSTs over the inner Scotian Shelf produced by sub-model L3 of the NCO- 
PS-LB with the SST measured by the Moderate Resolution Imaging Spectroradiometer (MODIS, Chris Jones, personal communication 2008). It should be noted that the MODIS measures SST from a thin "skin" surface layer, while the model temperatures shown in Figs. 12 and 13 are at 1.5 m, which should be cooler than the satellite measured SSTs during the study period as expected.

The simulated near-surface (at $1.5 \mathrm{~m}$ ) temperatures at 1800 UTC 1 July 2006 produced by sub-model L3 are characterized by relatively cool temperatures near the coast and deep waters to the southwest of Halifax and relatively warmer offshore with two noticeable pools of cool surface waters which agrees with the general horizontal features of the remote sensing MODIS SSTs shown in Fig. 12b. At 1800 UTC 3 July 2006 (Fig. 13), the coastal upwelling associated with the local wind forcing is more prevailing, which also agrees well with the MODIS SSTs. There are large differences, however, between the simulated and observed SSTs over the shelf break off the southwestern Scotian Shelf, where the simulated SSTs are much cooler than the satellite remote sensing SSTs.

We next compare the simulated temperatures and sa-
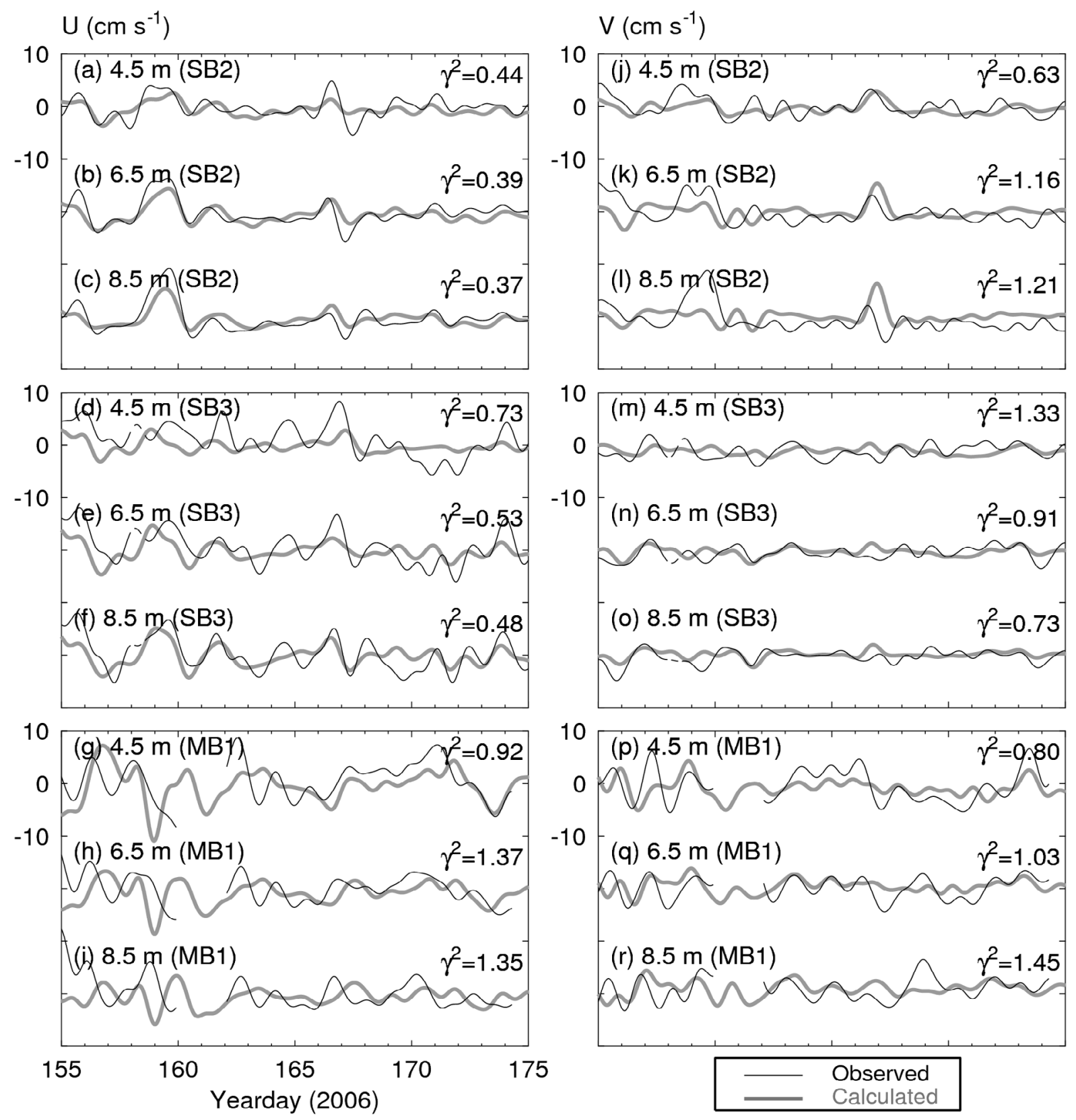

Fig. 11. Comparison of observed (black) and simulated (light gray) non-tidal currents at different depths at sites MB1, SB2, and SB3 in Lunenburg Bay. The simulated results are produced by sub-model L5. 


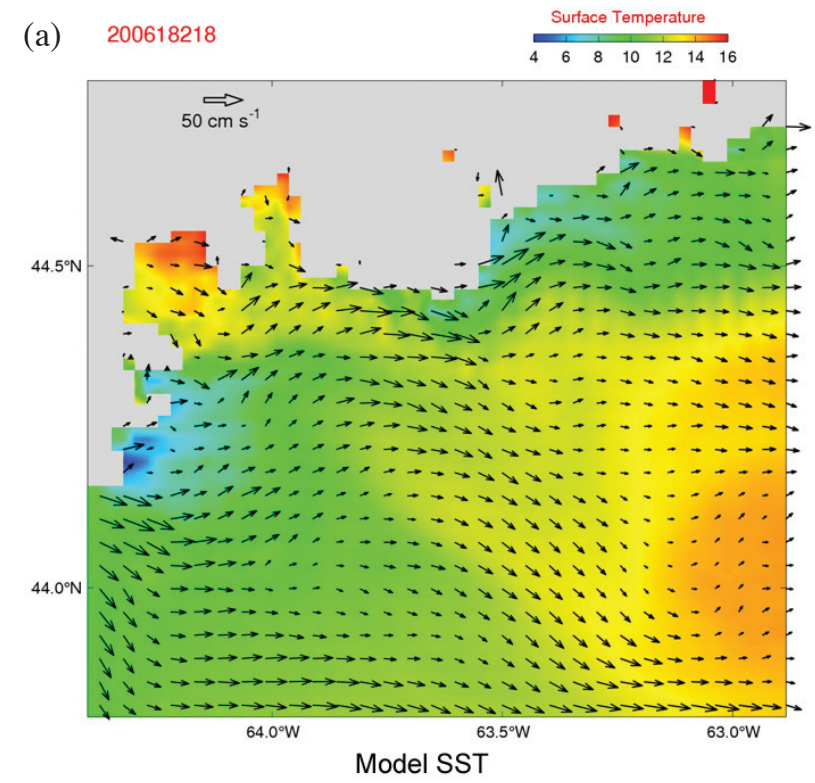

(b)
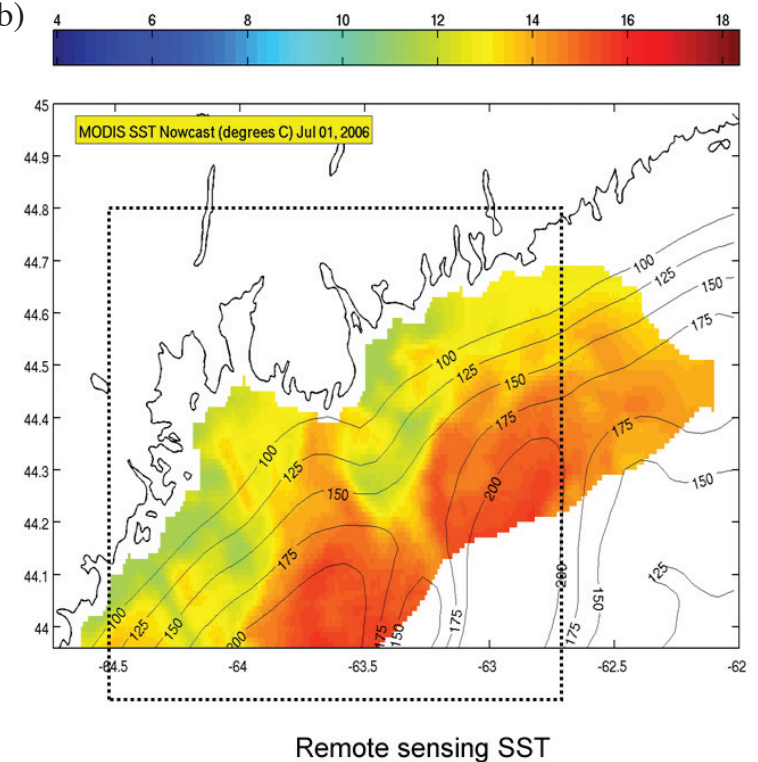

Fig. 12. (a) The near-surface temperature produced by sub-model L3 and (b) satellite remote sensing sea-surface temperature based on MODIS data over the inner Scotian Shelf on 1 July 2006. The area marked by the black dashed box in (b) is the domain of sub-model 3 shown in (a).

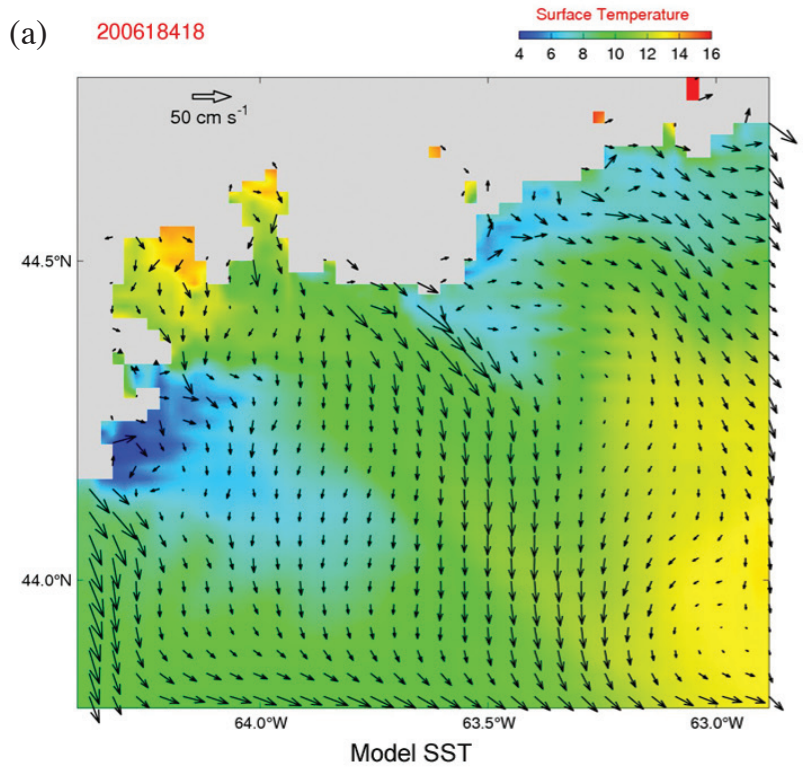

(b)

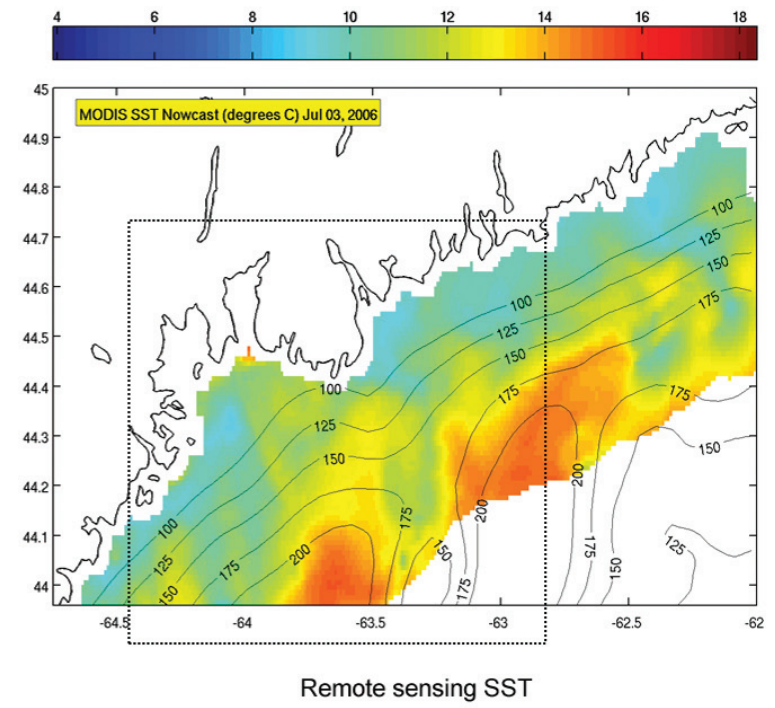

Fig. 13. (a) The near-surface temperature produced by sub-model L3 and (b) satellite remote sensing sea-surface temperature based on MODIS data over the inner Scotian Shelf on 3 July 2006. The area marked by the black dashed box in (b) is the domain of sub-model 3 shown in (a).

linities produced by sub-model L5 at sites SB2 and SB3 in LB with the observations during the study period. Figure 14 demonstrates the observed temperatures at the two sites had significant sub-tidal variability with a gradual warming trend (due to generally positive sea surface heat fluxes) in the upper water column from day 155 to 166 . Vertical temperature stratifications were present during this period, except for two storm events around days 159 and 167, respectively. The vertical temperature stratification was reduced signifi- cantly during the two storm events and reestablished gradually after the storms. The observed near-surface salinities at SB2 decreased from about 30 psu on day 155 and reached a minimum of about 27 psu on day 163. In comparison with the observations at SB2, similar low-frequency variability also occurred in the observed near-surface salinities at site SB3, but with smaller amplitudes. Significant low-frequency variabilities also appeared in the observed salinities at the two deeper depths at the two sites. 

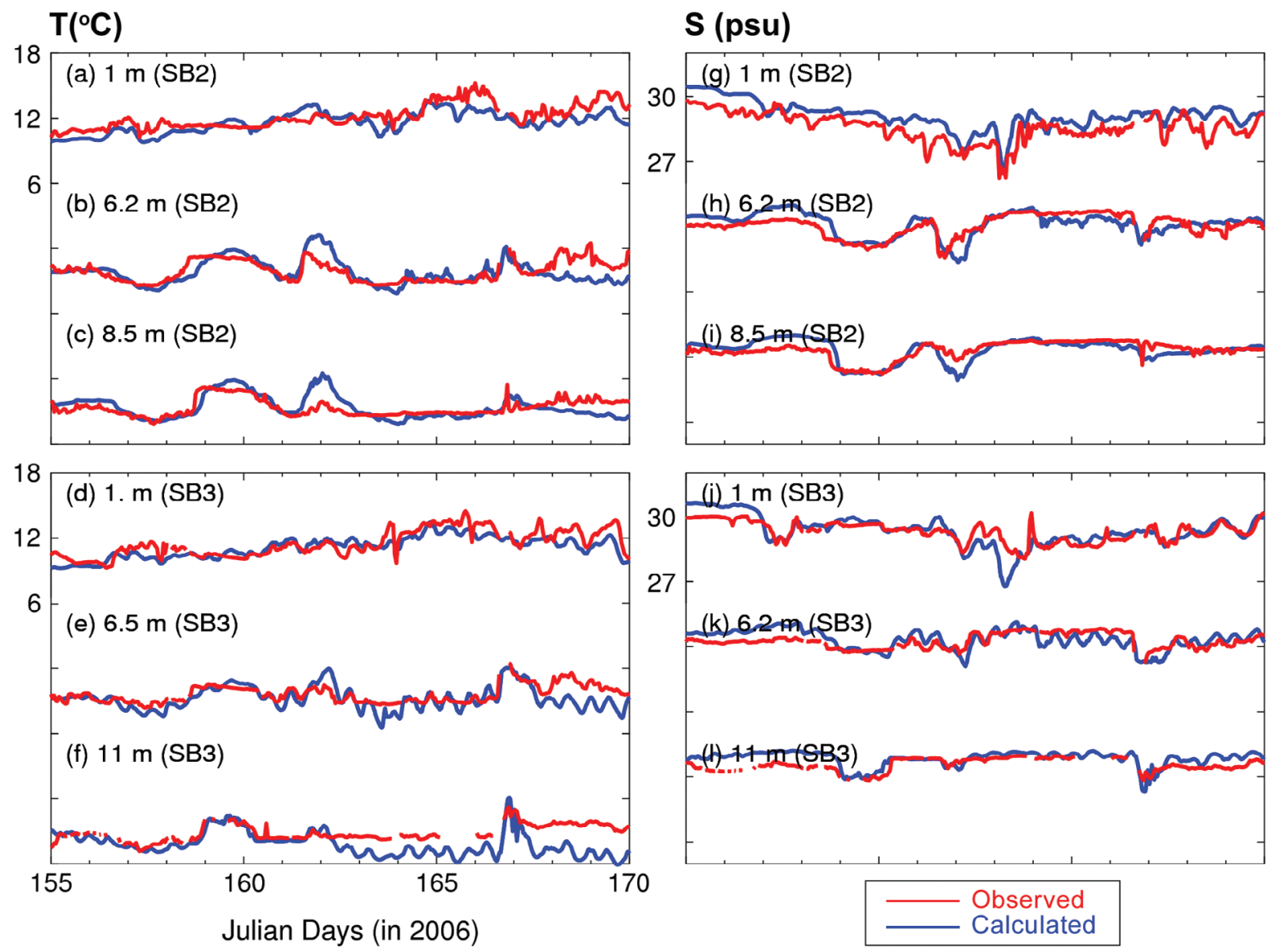

Fig. 14. Comparison of observed (red) and simulated (blue) temperature and salinity at two depths at mooring sites SB2 and SB3 in Lunenburg Bay. The simulated results are produced by sub-model L5.

In comparison with the hydrographic observations at the two sites, sub-model L5 of the NCOPS-LB has certain skills in hindcasting the observed temporal and vertical variations of temperatures and salinities at the two sites during this period. It should be noted that sub-model L5 overestimates the downwelling event around day 161, underestimates the observed sub-surface temperatures at $11 \mathrm{~m}$ at SB3, and over predicts the high-frequency variability in sub-surface temperatures and salinities at 6.5 and $11 \mathrm{~m}$ at $\mathrm{SB} 3$, for which the exact reasons are unknown.

\section{SUMMARY AND CONCLUSION}

A five-level nested-grid coastal ocean circulation modeling system (NCOPS-LB) was developed for Canadian Atlantic coastal waters. The nested-grid system was constructed from a prototype operational shelf circulation prediction system based on the $\sigma$-level POM (Thompson et al. 2007) and a coastal circulation model based on the freesurface of CANDE (Zhai et al. 2008a), with five relocatable sub-models. The outermost sub-model simulates the storm surges and barotropic shelf waters over the eastern Canadian continental shelf from Labrador Shelf to the Gulf of Maine. The innermost sub-model simulates the three dimensional currents and hydrographic distributions over Lunenburg Bay (LB) of Nova Scotia. The NCOPS-LB is forced by the atmospheric forcing calculated from three-hourly numerical weather forecasts provided by the Meteorological Service of Canada and tidal forcing produced by WebTide (with five major tidal constituents) along the open boundaries of sub-model L2. The NCOPS-LB was used to simulate the three-dimensional circulation and water mass distributions in June and July 2006, with a special emphasis on the storminduced circulation during tropical storm Alberto. The model results suggest that the circulation in LB over coastal waters of the inner Scotian Shelf is affected strongly by tides, local wind forcing, and the remotely generated waves.

The model results produced by the NCOPS-LB were compared with the observations made by a multidisciplinary ocean observing system in Lunenburg Bay. It was demonstrated the nested-grid system has reasonable skills in simulating the sea levels and tidal currents, but performs less well in simulating non-tidal currents and hydrography during the study period, due partially to less realistic repre- 
sentations of model forcing and due partially to the model deficiency in simulating the interaction of coastal circulation and upwelling with topography and non-linear dynamics and subgrid-scale mixing over coastal waters.

Acknowledgements The authors wish to thank Li Zhai, Kyoko Ohashi, Keith Thompson, Jun Zhao, Liang Wang, Hal Ritchie, Mike Dowd, Hal Ritchie, Serge Desjardins, Doug Schillinger, Alex Hay, and John Cullen for their contributions in developing the NCOPS-LB. This study was supported by the Canadian Foundation for Climate and Atmospheric Studies (CFCAS), the NSERC/MARTEC/MSC Industrial Research Chair program and NSERC discovery grant to JS.

\section{REFERENCES}

Brachya, V., F. Juhasz, A. Pavasovic, and I. Trumbic, 1994: Guidelines for Integrated Management of Coastal and Marine Areas with Special Reference to the Mediterranean Basin, Split, Croatia, PAP/RAC (MAP-UNEP), $80 \mathrm{pp}$.

Chapman, D. C., 1985: Numerical treatment of cross-shelf open boundaries in a barotropic coastal ocean model. $J$. Phys. Oceanogr., 15, 1060-1075, doi: 10.1175/15200485(1985)015<1060:NTOCSO>2.0.CO;2. [Link]

Davies, A. M. and R. A. Flather, 1978: Computing extreme meteorologically induced currents, with application to the northwest European continental shelf. Cont. Shelf Res., 7, 643-683, doi: 10.1016/0278-4343(87)90010-0. [Link]

Dupont, F., C. G. Hannah, D. A. Greenburg, J. Y. Cherniawsky, and C. E. Naimie, 2002: Modelling system for tides. Can. Tech. Rep. Hydrogr. Ocean Sci., 221, Fisheries and Oceans Canada, Bedford Institute of Oceanography, Dartmouth, Canada, 72 pp.

Geshelin, Y., J. Sheng, R. J. Greatbatch, 1999. Monthly mean climatologies of temperature and salinity in the western North Atlantic. Can. Data Rep. Hydrogr. Ocean Sci., 153, 62.

Gill, A. E., 1982: Atmosphere-Ocean Dynamics. Academic, San Diego, CA, USA, 662 pp.

Large, W. G. and S. Pond, 1981: Open ocean momentum flux measurements in moderate to strong winds. $J$. Phys. Oceanogr., 11, 324-336, doi: 10.1175/1520-0485 (1981)011<0324:OOMFMI>2.0.CO;2. [Link]

Large, W. G., J. C. McWilliams, and S. C. Doney, 1994: Oceanic vertical mixing: A review and a model with a nonlocal boundary layer parameterization. Rev. Geophys., 32, 363-403, doi: 10.1029/94RG01872. [Link]

Marchesiello, P., J. C. McWilliams, and A. Shchepetkin, 2001: Open boundary conditions for long-term integration of regional oceanic models. Ocean Model., 3, 1-21, doi: 10.1016/S1463-5003(00)00013-5. [Link]
Mellor, G. L., 2004: Users Guides for the Three-Dimensional, Primitive-Equation Ocean Circulation Model, $56 \mathrm{pp}$.

Mellor, G. L. and T. Yamada, 1982: Development of a turbulence closure model for geophysical fluid problems. Rev. Geophys. Space Phys., 20, 851-875, doi: 10.1029/ RG020i004p00851. [Link]

Ohashi, K., J. Sheng, K. R. Thompson, C. G. Hannah, and H. Ritchie, 2009: Numerical study of three-dimensional shelf circulation on the Scotian Shelf using a shelf circulation model. Cont. Shelf. Res., 29, 2138-2156. doi: 10.1016/j.csr.2009.08.005. [Link]

Orlanski, I., 1976: A simple boundary condition for unbounded hyperbolic flows. J. Comput. Phys., 21, 251269, doi: 10.1016/0021-9991(76)90023-1. [Link]

Pawlowiz, R., B. Beardsley, and S. Lentz, 2002: Classical tidal harmonic analysis including error estimates in MATLAB using T_TIDE. Comput. Geosci., 28, 929937, doi: 10.1016/S0098-3004(02)00013-4. [Link]

Sheng, J. and L. Wang, 2004: Numerical study of tidal circulation and nonlinear dynamics in Lunenburg Bay, Nova Scotia. J. Geophys. Res., 109, C10018, doi: 10.1029/ 2004JC002404. [Link]

Sheng, J. and B. Yang, 2008: A five-level nested-grid coastal circulation prediction system for Canadian Atlantic coastal waters. Proceedings of $10^{\text {th }}$ International Conference on Estuarine and Coastal Modeling, 38-56.

Sheng, J., D. G. Wright, R. J. Greatbatch, and D. E. Dietrich, 1998: CANDIE: A new version of the DieCAST ocean circulation model. J. Atmos. Ocean. Technol., 15, 14141432, doi: 10.1175/1520-0426(1998)015<1414:CANV OT>2.0.CO;2. [Link]

Sheng, J., J. Zhao, and L. Zhai, 2009: Examination of circulation, dispersion and connectivity in Lunenburg Bay of Nova Scotia using a nested-grid circulation model. J.Mar. Syst., 77, 350-365, doi: 10.1016/j.jmarsys. 2008. 01.013. [Link]

Smagorinsky, J., 1963: General circulation experiments with the primitive equation. I. The basic experiment. Mon. Weather Rev., 91, 99-164, doi: 10.1175/15200493(1963)091<0099:GCEWTP>2.3.CO;2. [Link]

Thompson, K. R. and J. Sheng, 1997: Subtidal circulation on the Scotian Shelf: Assessing the hindcast skill of a linear, barotropic model. J. Geophys. Res., 102, 2498725003, doi: 10.1029/97JC00368. [Link]

Thompson, K. R., D. E. Kelley, D. Sturley, B. Topliss, and R. Leal, 1998: Nearshore circulation and synthetic aperture radar: An exploratory study. Int. J. Remote Sens., 19, 1161-1178, doi: 10.1080/014311698215667. [Link]

Thompson, K. R., K. Ohashi, J. Sheng, J. Bobanovic, and J. $\mathrm{Ou}, 2007$ : Suppressing bias and drift of coastal circulation models through the assimilation of seasonal climatologies of temperature and salinity. Cont. Shelf Res., 
27, 1303-1316, doi: 10.1016/j.csr.2006.10.011. [Link]

UNEP, 1984: Prospects for global ocean pollution monitoring, Report 47, United Nations Environment Program, $53 \mathrm{pp}$.

Wang, L., J. Sheng, A. E. Hay, and D. J. Schillinger, 2007: Storm-induced circulation in Lunenburg Bay of Nova Scotia: Observations and numerical simulations. J. Phys. Oceanogr., 37, 873-895, doi: 10.1175/ JPO3031.1. [Link]

Wang, X., Y. Chao, C. Dong, J. Farrara, Z. Li, J. C. McWilliams, J. D. Paduan, and L. K. Rosefeld, 2009: Modeling tides in Monterey Bay, California. Deep-Sea Res., II, 56, 219-231, doi: 10.1016/j.dsr2.2008.08.012. [Link]

Warner, J. C., W. R. Geyer, and J. A. Lerezak, 2005: Nu- merical modeling of an estuary: A comprehensive skill assessment. J. Geophys. Res., 110, C05001, doi: 10.1029/2004JC002691. [Link]

Wilmott, C. J., 1981: On the validation of models. Phys. Geogr., 2, 184-194.

Zhai, L., J. Sheng, and R. J. Greatbatch, 2008a: Application of a nested-grid ocean circulation model to Lunenburg Bay of Nova Scotia: Verification against observations. J. Geophys. Res., 113, C02024, doi: 10.1029/ 2007JC004230. [Link]

Zhai, L., J. Sheng, and R. J. Greatbatch, 2008b: Baroclinic dynamics of wind-driven circulation in a stratified bay: A numerical study using models of varying complexity. Cont. Shelf Res., 28, 2357-2370, doi: 10.1016/j.csr. 2008.05.005. [Link] 